\title{
On Aethalometer measurement uncertainties and an instrument correction factor for the Arctic
}

\author{
John Backman ${ }^{1}$, Lauren Schmeisser ${ }^{2, a}$, Aki Virkkula ${ }^{1,3,4}$, John A. Ogren ${ }^{2,5}$, Eija Asmi ${ }^{1}$, Sandra Starkweather ${ }^{2,5}$, \\ Sangeeta Sharma ${ }^{6}$, Konstantinos Eleftheriadis ${ }^{7}$, Taneil Uttal ${ }^{5}$, Anne Jefferson ${ }^{2}$, Michael Bergin ${ }^{8}$, \\ Alexander Makshtas ${ }^{9}$, Peter Tunved ${ }^{10}$, and Markus Fiebig ${ }^{11}$ \\ ${ }^{1}$ Finnish Meteorological Institute, Atmospheric Composition Research, Helsinki, Finland \\ ${ }^{2}$ University of Colorado Boulder, Cooperative Institute for Research in Environmental Sciences, Boulder, USA \\ ${ }^{3}$ University of Helsinki, Department of Physics, Helsinki, Finland \\ ${ }^{4}$ Nanjing University, Joint International Research Laboratory of Atmospheric and Earth System Sciences, Nanjing, China \\ ${ }^{5}$ National Oceanic and Atmospheric Administration, Earth System Research Laboratory, Boulder, USA \\ ${ }^{6}$ Environment and Climate Change Canada, Climate Research Division, Downsview, Canada \\ ${ }^{7}$ Institute of Nuclear and Radiological Science and Technology, Energy and Safety, Environmental Radioactivity Laboratory, \\ NCSR “Demokritos”, Athens, Greece \\ ${ }^{8}$ Duke University, Civil and Environmental Engineering, Durham, USA \\ ${ }^{9}$ Russian Federal Service for Hydrometeorology and Environmental Monitoring, Arctic and Antarctic Research Institute, \\ St. Petersburg, Russia \\ ${ }^{10}$ Stockholm University, Department of Environmental Science and Analytical Chemistry, Stockholm, Sweden \\ ${ }^{11}$ NILU - Norsk institutt for luftforskning, Dept. Atmospheric and Climate Research (ATMOS), Kjeller, Norway \\ ${ }^{a}$ now at: University of Washington, Department of Atmospheric Sciences, Seattle, USA
}

Correspondence: John Backman (john.backman@fmi.fi)

Received: 12 September 2016 - Discussion started: 8 December 2016

Revised: 8 May 2017 - Accepted: 10 May 2017 - Published: 21 December 2017

\begin{abstract}
Several types of filter-based instruments are used to estimate aerosol light absorption coefficients. Two significant results are presented based on Aethalometer measurements at six Arctic stations from 2012 to 2014. First, an alternative method of post-processing the Aethalometer data is presented, which reduces measurement noise and lowers the detection limit of the instrument more effectively than boxcar averaging. The biggest benefit of this approach can be achieved if instrument drift is minimised. Moreover, by using an attenuation threshold criterion for data post-processing, the relative uncertainty from the electronic noise of the instrument is kept constant. This approach results in a time series with a variable collection time $(\Delta t)$ but with a constant relative uncertainty with regard to electronic noise in the instrument. An additional advantage of this method is that the detection limit of the instrument will be lowered at small aerosol concentrations at the expense of temporal resolution, whereas there is little to no loss in temporal resolution at high
\end{abstract}

aerosol concentrations $\left(>2.1-6.7 \mathrm{Mm}^{-1}\right.$ as measured by the Aethalometers). At high aerosol concentrations, minimising the detection limit of the instrument is less critical. Additionally, utilising co-located filter-based absorption photometers, a correction factor is presented for the Arctic that can be used in Aethalometer corrections available in literature. The correction factor of 3.45 was calculated for low-elevation Arctic stations. This correction factor harmonises Aethalometer attenuation coefficients with light absorption coefficients as measured by the co-located light absorption photometers. Using one correction factor for Arctic Aethalometers has the advantage that measurements between stations become more inter-comparable. 


\section{Introduction}

Black carbon (BC) and soot, which originate from incomplete combustion, are particularly potent absorbers of solar radiation and comprise a complex part of the climate system (Bond et al., 2013). Light absorbing particles, including $\mathrm{BC}$ and soot, influence the aerosol radiative forcing (ARF) by warming the atmosphere, changing the aerosol singlescattering albedo, and potentially altering cloud droplet evaporation and lifetime (Koch and Del Genio, 2010). In addition, trace amounts of absorbing particles deposited on snow can perturb snow grain size and thus lower the snow albedo (Hadley and Kirchstetter, 2012; Wiscombe and Warren, 1980a, b); a low albedo favours melting. Polar regions are particularly sensitive to changes in surface albedo, which subsequently impacts sea ice, snow cover, and ultimately surface temperature (Holland and Bitz, 2003; Serreze and Barry, 2011; Serreze et al., 2009). This polar amplification results in enhanced ice melt and more open water (Johannessen et al., 2004; Serreze et al., 2009). Brown carbon (BrC) absorbs sunlight primarily in the ultraviolet-visible region of the solar spectrum (Andreae and Gelencsér, 2006; Bergstrom et al., 2007), whereas the BC absorption efficiency is relatively uniform across the UV to near-infrared solar spectrum.

Given that $\mathrm{BC}$ is a particularly potent perturbing agent, insitu measurements of $\mathrm{BC}$ are important. A widely used technique to measure light absorption by aerosol particles is with filter-based absorption instruments such as the Aethalometer (e.g. Weingartner et al., 2003), the particle soot absorption photometer (PSAP; Bond et al., 1999; Virkkula et al., 2005), and the multi-angle absorption photometer (MAAP; Petzold and Schönlinner, 2004; Petzold et al., 2005). These instruments report either equivalent black carbon (eBC) mass concentrations or light absorption coefficients (Petzold et al., 2013).

The high variability of eBC, particularly in polar, highaltitude, and coastal regions, makes measurements with Aethalometers challenging. During clean periods, the eBC concentrations can easily be below the detection limit of the instrument. Data treatment methods such as boxcar averaging can improve the detection limit of the instrument.

An alternative method to reduce noise in Aethalometers has been proposed (Hagler et al., 2011). In this work, a criterion from Hagler et al. (2011) is used; an attenuation change ( $\triangle \mathrm{ATN})$ threshold needs to be exceeded for postprocessing calculations to be invoked. Instead of using this one criterion for boxcar averaging intervals, $\triangle \mathrm{ATN}$ is used in the post-processing calculations using the Aethalometer equation. Here we explore this alternative method from a measurement uncertainty perspective and show that a constant relative uncertainty can be achieved using this one criterion for data post-processing. The result is a time series with a time resolution which is adapted to the measured aerosol concentration. The best performance of this method is achieved when drift in the Aethalometer is at a minimum.
While it is well known that Aethalometer measurements require some form of post-processing (Arnott et al., 2005; Collaud Coen et al., 2010; Schmid et al., 2006; Virkkula et al., 2007; Weingartner et al., 2003), the purpose of this paper is not to add a correction algorithm to the literature but to show how to reduce noise in Aethalometer measurements more effectively. This paper uses data from Arctic sites, regions with low signal and high susceptibility to ARF from $\mathrm{eBC}$, to examine noise reduction in the Aethalometer signal. Aethalometer instruments have been used to make measurements in the Arctic since the 1980s (e.g. Bodhaine, 1995; Sharma et al., 2006, 2013).

Using the adaptive collection time method of data collection we present an Arctic correction factor $\left(C_{\mathrm{f}}\right)$ value to harmonise Aethalometer absorption measurements to other filter-based light absorption photometers. This correction factor can be used in existing Aethalometer correction schemes available in literature.

\section{Measurements and instruments}

The data used in this study comprise 3 years of measurements (2012-2014) at six Arctic stations. The actual eBC climatology of the stations will be presented in a following paper. Below we provide information about station location, operations, and environs, as well as the instruments deployed at each site. Each site has at least an Aethalometer and an additional filter-based absorption photometer. The instruments are summarised in Table 1.

\subsection{Measurement sites}

\subsubsection{Barrow}

The Barrow observatory is located on the northernmost coast of Alaska, just $5 \mathrm{~km}$ north-east of the town of Barrow, Alaska (population $\sim 4200$ ), and $2 \mathrm{~km}$ from the Arctic Ocean coast, at an elevation of $11 \mathrm{~m}$ above sea level (a.s.l.) and at coordinates $71.323^{\circ} \mathrm{N}$ and $156.612^{\circ} \mathrm{W}$. The site is primarily influenced by regional air masses originating from the Beaufort Sea, though the station also measures pollution coming from the nearby town. All air masses originating from the direction of the town are marked as contaminated, and those data are not used in this analysis.

A 7-wavelength Magee AE31 Aethalometer has been operating at the station since 2010. The co-located light absorption instrument is the continuous light absorption photometer (CLAP; Ogren et al., 2017) that has been collecting aerosol absorption data since 2011 and was built by National Oceanic and Atmospheric Administration (NOAA). Previous descriptions of the aerosol optical property climatology at Barrow can be found in Bodhaine $(1983,1995)$ and Delene and Ogren (2002). 
Table 1. Overview of instruments at the respective measurement stations. The flow rates are mean values in standard litres per minute (slpm). TOT means that it is a total aerosol inlet with no cutoff size. Filter change settings reported as either ATN or filter transmittance (Tr).

\begin{tabular}{|c|c|c|c|c|c|c|}
\hline Site & Instruments & Model & Wavelengths $(\mathrm{nm})$ & Inlet & $\begin{array}{l}\text { Flow } \\
\text { rate } \\
\text { (slpm) }\end{array}$ & Filter change at \\
\hline Alert & $\begin{array}{l}\text { Aethalometer } \\
\text { PSAP }\end{array}$ & $\begin{array}{l}\mathrm{AE} 31 \\
\mathrm{RR}^{\mathrm{a}} 3 \lambda\end{array}$ & $\begin{array}{l}370,470,520,590,660,880,950 \\
467,530,660\end{array}$ & $\begin{array}{l}\text { TOT } \\
\text { PM }_{10}\end{array}$ & $\begin{array}{l}3.9 \\
1.1\end{array}$ & $\begin{array}{l}\mathrm{ATN}=75 \\
\mathrm{Tr}=0.7\end{array}$ \\
\hline Summit & $\begin{array}{l}\text { Aethalometer } \\
\text { CLAP }\end{array}$ & $\begin{array}{l}\text { AE16 } \\
3 \lambda\end{array}$ & $\begin{array}{l}880 \\
467,528,652\end{array}$ & $\begin{array}{l}\mathrm{PM}_{2.5} \\
\mathrm{PM}_{2.5}\end{array}$ & $\begin{array}{l}6.3 \\
0.6\end{array}$ & $\begin{array}{l}\mathrm{ATN}=75 \\
\operatorname{Tr}=0.7\end{array}$ \\
\hline Barrow & $\begin{array}{l}\text { Aethalometer } \\
\text { CLAP }\end{array}$ & $\begin{array}{l}\mathrm{AE} 31 \\
3 \lambda\end{array}$ & $\begin{array}{l}370,470,520,590,660,880,950 \\
467,528,652\end{array}$ & $\begin{array}{l}\mathrm{PM}_{10} \\
\mathrm{PM}_{10} \\
\end{array}$ & $\begin{array}{l}4.8 \\
1.3 \\
\end{array}$ & $\begin{array}{l}\mathrm{ATN}=99 \\
\mathrm{Tr}=0.7\end{array}$ \\
\hline Tiksi & $\begin{array}{l}\text { Aethalometer } \\
\text { MAAP }\end{array}$ & $\begin{array}{l}\text { AE31 } \\
5012\end{array}$ & $\begin{array}{l}370,470,520,590,660,880,950 \\
637^{\mathrm{c}}\end{array}$ & $\begin{array}{l}\mathrm{PM}_{10} \\
\mathrm{PM}_{10}\end{array}$ & $\begin{array}{l}4.9 \\
5.6\end{array}$ & $\begin{array}{l}\mathrm{ATN}=75 \\
\mathrm{ATN}=20\end{array}$ \\
\hline Pallas & $\begin{array}{l}\text { Aethalometer } \\
\text { MAAP }\end{array}$ & $\begin{array}{l}\text { AE31 } \\
5012\end{array}$ & $\begin{array}{l}370,470,520,590,660,880,950 \\
637^{c}\end{array}$ & $\begin{array}{l}\text { TOT } \\
\mathrm{PM}_{2.5}\end{array}$ & $\begin{array}{l}2.9 / 4.0 \\
8.7\end{array}$ & $\begin{array}{l}8 \mathrm{~h} \\
\mathrm{ATN}=50\end{array}$ \\
\hline Zeppelin & $\begin{array}{l}\text { Aethalometer } \\
\text { PSAP }\end{array}$ & $\begin{array}{l}\mathrm{AE} 31 \\
1 \lambda^{\mathrm{b}}\end{array}$ & $\begin{array}{l}370,470,520,590,660,880,950 \\
525\end{array}$ & $\begin{array}{l}\text { TOT } \\
\text { TOT }\end{array}$ & $\begin{array}{l}7.5 \\
0.9\end{array}$ & $\begin{array}{l}\mathrm{ATN}=75 \\
\mathrm{Tr}=0.7\end{array}$ \\
\hline
\end{tabular}

${ }^{\text {a }}$ Radiance research; ${ }^{\mathrm{b}}$ Custom-built $1 \lambda$ PSAP; ${ }^{\mathrm{c}}$ Müller et al. (2011)

\subsubsection{Alert}

Alert is located in Nunavut, Canada, $12 \mathrm{~km}$ west of Cape Sheridan, at $82.492^{\circ} \mathrm{N}$ and $62.508^{\circ} \mathrm{W}$ and at an elevation of $8 \mathrm{~m}$ a.s.l. The monitoring station is operated by Environment and Climate Change Canada. Alert is the northernmost site of those analysed here, located just $817 \mathrm{~km}$ from the North Pole. Given the remote location, the aerosols there are not heavily influenced by human populations. The site is near the coast, which is ice covered in the winter but turns to open ocean during summer. A 7-wavelength Magee AE31 Aethalometer has been running at Alert from 2008 to present. Co-located light absorption measurements were made with a 3-wavelength PSAP from 2007 to present. More information on black carbon measurements at Alert can be found in Sharma et al. (2002).

\subsubsection{Summit}

The monitoring station at Summit, Greenland, is located at $72.580^{\circ} \mathrm{N}$ and $38.480^{\circ} \mathrm{W}$, and at $3216 \mathrm{~m}$ a.s.l., is the highest in elevation of the six sites. Measurements of equivalent black carbon at Summit are supported and operated by Duke University in collaboration with the NOAA Earth Systems Research Laboratory. Although there are many established scientific operations at the Summit site that necessitate activities that produce anthropogenic aerosols, the site is generally very remote and measures very low aerosol concentrations. Equivalent black carbon measurements here have been made with a 1-wavelength $(880 \mathrm{~nm})$ Magee AE16 Aethalometer from 2003 to present. The co-located light absorption pho- tometer at Summit is a multi-wavelength CLAP, running at the site from 2011 to present.

\subsubsection{Zeppelin}

The Zeppelin Mountain observatory is located at $475 \mathrm{~m}$ a.s.l. near the small research village of Ny-Ålesund on the island of Svalbard at $78.907^{\circ} \mathrm{N}$ and $11.889^{\circ} \mathrm{E}$. The monitoring station is owned by the Norwegian Polar Institute and operated by the Norwegian Institute for Air Research, and the most recent version of the station building was established in the year 2000 . The site is typically located above the inversion layer and thus measures air masses with minimal contamination. The observatory has long-term measurements of equivalent black carbon with Magee Aethalometers, namely AE9 from 1998 to 1999 and AE31 from 2001 to present (Eleftheriadis et al., 2009), and co-located light absorption measurements with a 1-wavelength PSAP.

\subsubsection{Pallas}

The Pallas measurement station is located in the Finnish Arctic in the Municipality of Muonio. The measurement station is operated by the Finnish Meteorological Institute. The main measurement building housing the instruments used in this study is located on top of the Sammaltunturi fell. The top of the fell is at an altitude of $565 \mathrm{~m}$ a.s.l. and above the tree line. The coordinates of the station are $67.973^{\circ} \mathrm{N}, 24.116^{\circ} \mathrm{E}$. There are no major local sources close to the station, and the surrounding terrain is forested, consisting of pine, spruce, and birch trees in addition to barren fells. 
The 7-wavelength Magee AE31 Aethalometer is connected to the total aerosol inlet which is heated in order to lower the relative humidity (RH) and causes cloud drops to evaporate. The co-located light absorption photometer is a MAAP (Thermo Scientific, model 5012). The MAAP is connected to a heated $\mathrm{PM}_{2.5}$ inlet to lower the relative humidity. The different size cuts of the instruments could bias the Aethalometer towards higher absorption coefficients than the MAAP. A more thorough description of the site is provided by Hatakka et al. (2003).

\subsubsection{Tiksi}

The Tiksi measurement station is located in northern Siberia in Russia. The station is located $500 \mathrm{~m}$ from the coast of the Laptev Sea at an altitude of $30 \mathrm{~m}$ a.s.l. at $71.596^{\circ} \mathrm{N}$, $128.889^{\circ} \mathrm{E}$. The site is surrounded by tundra. The station is a cooperation between the Russian Federation's Roshydromet, the US National Oceanic and Atmospheric Administration, the US National Science Foundation, and the Finnish Meteorological Institute. The station is located $\approx 4 \mathrm{~km}$ south of the town of Tiksi, which comprises the sole source of local air pollution. The data were screened using local wind direction and aerosol size distribution data to omit local pollution from the town (Asmi et al., 2016).

The measurement instruments used in this study consist of a 7-wavelength Aethalometer (Magee model AE31) and a MAAP (model 5012). The instruments are connected to a $\mathrm{PM}_{10}$ inlet with self-regulating heating to avoid the build-up of ice on the inlet. By raising the temperature of the sample air to room temperature, the sample RH is kept below $30 \%$ (Asmi et al., 2015).

\subsection{Data processing}

\subsubsection{The Aethalometer}

The Aethalometer theory of operation relies on the measurement of light transmitted through a fibre filter as aerosol particles are collected on the filter. The filter is illuminated by a light source from one side with the detectors located on the other side of the filter. Light is transmitted through a pristine part of the filter with an intensity $I_{0}$. The light that traverses through the part where aerosol particle deposit is transmitted with an intensity $I$. The Aethalometer calculates, and reports, filter attenuation (ATN) as described in Eq. (1) (e.g. Weingartner et al., 2003).

$\operatorname{ATN}=-100 \ln \left(\frac{I}{I_{0}}\right)$

The term $I / I_{0}$ represents the transmission of light through the filter and is referred to as the filter transmittance. The factor of 100 in Eq. (1) is there for numerical convenience and will for this reason also be included throughout this work. The attenuation coefficient $\left(\sigma_{0}\right)$ can be written in the form (e.g. Weingartner et al., 2003)

$\sigma_{0}=\frac{A}{Q \Delta t} \frac{\Delta \mathrm{ATN}}{100}$.

In Eq. (2), $A$ is the filter spot size area, $Q$ is the sample flow rate, and $\Delta t$ is the time between the light intensity measurements. The term $\Delta \mathrm{ATN}$ is the change in ATN over the time $\Delta t$, which is here called the collection time. When the fibre filter is loaded with aerosol, and the transmission of light through the filter has dropped too much, the filter spot needs to be changed. In the Aethalometer, filter changes can be set to occur automatically at an ATN value set by the operator. Alternatively, the filter can be set to change after a given time.

Although the Aethalometer actually measures $\sigma_{0}$, the instrument output is equivalent black carbon mass concentration (Petzold et al., 2013). The conversion from $\sigma_{0}$ to eBC is done using a wavelength-dependent mass attenuation cross section $\left(\mathrm{MAC}_{\mathrm{AE}}\right.$ ) of $16.62 \mathrm{~m}^{2} \mathrm{~g}^{-1}$ (at $880 \mathrm{~nm}$ ), scaling inversely with wavelength (e.g. Arnott et al., 2005).

The firmware of the Aethalometer uses an internal collection time $\Delta t$ which is $2 \leq \Delta t \leq 5 \mathrm{~min}$. This is the inner data processing cycle of the AE31 Aethalometer. Any longer averaging times set by the operator will commence an outer cycle, which will average the readings obtained during the inner cycle. Therefore, the averaging time $\left(t_{\text {avg }}\right)$ that can be set for the instrument by the operator is restricted to multiples of $5 \mathrm{~min}$. In other words, the output of the outer cycle is an average of the inner cycle with a $\Delta t$ of $5 \mathrm{~min}$. This is not always ideal since at very pristine sites a collection time of $5 \mathrm{~min}$ is not long enough, resulting in noisy data.

Choosing a longer averaging time (the so-called outer cycle) will reduce noise and, therefore, the detection limit of the instrument, at a rate of $t_{\mathrm{avg}}^{-0.5}$. Increasing $t_{\mathrm{avg}}$, however, results in a reduction of temporal resolution. Moreover, when $t_{\text {avg }}>\Delta t$ the instrument output can no longer be reproduced using Eq. (2) since the data that comprise the inner cycle are no longer reported by the instrument. Thus, the greatest versatility of post-processing can be achieved when $t_{\text {avg }}$ is equal to $\Delta t$; i.e. $t_{\text {avg }} \leq 5 \mathrm{~min}$ for the Aethalometers in this study.

One can circumvent the outer cycle by data postprocessing and achieve a lower detection limit. Included in the standard long-format output of the AE31 and AE16 Aethalometer models are the ATN values at the end of the averaging period, along with the aerosol flow rate. Thus, the standard output data can be used to post-process the data using Eq. (2) for an arbitrary value of $\Delta t$; i.e. an arbitrary collection time. The term $\triangle \mathrm{ATN}$ is then simply the change in ATN from the time $t$ to $t+\Delta t$; i.e. $\Delta \mathrm{ATN}=\operatorname{ATN}_{t+\Delta t}-$ $\operatorname{ATN}_{t}$.

The benefit of this post-processing approach is that it reduces noise better than the boxcar averaging of the firmware. This is discussed and shown further on. This approach for reducing noise in Aethalometer measurements was originally suggested by Hagler et al. (2011). In their work, a $\triangle A T N$ 
change was used as a criterion for boxcar averaging, whereas, here, $\triangle \mathrm{ATN}$ is used in the calculations. Previous work using a PSAP has shown that the collection time approach can greatly reduce the noise of filter attenuation measurements (Springston and Sedlacek, 2007) to produce a time series with an adaptive collection time (Hagler et al., 2007). In this work, the method is elaborated on using uncertainty analysis, specifically for Aethalometers.

\subsection{Arctic Aethalometer correction factor}

The actual aerosol light absorption coefficient of the initially suspended particles is not $\sigma_{0}$. When aerosol particles deposit onto a filter, they will inevitably interact with the filter. The realisation of this has resulted in a variety of different dataprocessing correction schemes for the Aethalometer and the PSAP (Arnott et al., 2005; Bond et al., 1999; Collaud Coen et al., 2010; Schmid et al., 2006; Virkkula et al., 2005, 2007; Weingartner et al., 2003). The purpose of these corrections is to derive the actual light absorption coefficient $\left(\sigma_{\mathrm{ap}}\right)$ of the suspended particles devoid of filter-induced artefacts.

The Arctic measurement sites included in this study all have the same type of measurement instrument, namely the Aethalometer model AE31, except for Summit, which is an AE16 model Aethalometer. The benefit of having the same type and model of instrument is that measurement artefacts for the same type of instrument would be expected to be more similar than between different types of instruments. The comparison of aerosol properties between different sites should be more robust when all sites have the same type of instrument than if the instruments would differ from site to site. Both the AE31 and AE16 model use the same type of filter (Pallflex Q250F). However, it still has to be acknowledged that artefacts can differ between different stations depending on the difference in aerosol properties even though the same type of instrument is used.

For the sake of inter-comparability, a relative normalisation factor is introduced to harmonise the determination of the absorption coefficient at the Arctic stations. The harmonisation factor is calculated as

$C_{\mathrm{f}}=\frac{\sigma_{0}}{\sigma_{\mathrm{ap}}}$,

where $\sigma_{\text {ap }}$ is the light absorption coefficient as measured by co-located filter-based absorption measurements. The colocated instruments are discussed in more detail in the next section. The interpretation of the correction factor is in essence how much greater the attenuation coefficient is in comparison to the light absorption coefficient of the colocated filter-based absorption photometers which have been corrected for loading and scattering artefacts. Thus, $C_{\mathrm{f}}$ will effectively be an inter-instrument comparison factor.

This correction factor can be used in many of the available correction algorithms in the place of the multiple scattering correction factor $\left(C_{\text {ref }}\right)$; see Collaud Coen et al. (2010) Table 2 for a list. However, the $C_{\mathrm{f}}$ values reported here are not multiple scattering correction factors because no true reference absorption measurements were available. The purpose of the $C_{\mathrm{f}}$ values here is to provide a general value that can

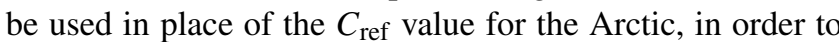
harmonise the determination of $\sigma_{\mathrm{ap}}$ from Aethalometers in the Arctic with other methods for determining aerosol light absorption coefficients.

\subsection{Co-located filter-based absorption instruments}

The Arctic sites in this study were chosen based on the criterion that they all have Aethalometers and an additional colocated filter-based photometer measuring aerosol light absorption coefficients. The additional instrument is either a MAAP, PSAP, or CLAP. These instruments will provide the $\sigma_{\text {ap }}$ that is needed to calculate $C_{\mathrm{f}}$ for the sites, using Eq. (3). The MAAP is a filter-based absorption instrument that, in addition to transmittance measurements through the filter, also measures the back-scattered light at two angles (Petzold and Schönlinner, 2004). This allows for a radiative transfer scheme to be applied since the back-scattered light at multiple angles can be used to distinguish between diffusely scattered light and Gaussian scattered light. This information is then used to calculate the diffuse fraction of light scattered back by the filter in order to account for multiple scattering and apparent absorption effects by solving the radiative transfer equation from the measurements on the filter.

The PSAP and CLAP instruments measure transmission, and therefore are based on Eqs. (1) and (2). Both instruments use the same type of filter, and the optical design of the CLAP is very similar to the PSAP. The CLAP differs from the PSAP in that, instead of a single sample spot on a $10 \mathrm{~mm}$ filter, it has eight sample spots on a $47 \mathrm{~mm}$ filter. Solenoid valves are used to switch to the next sample spot once the filter transmittance reaches 0.7. Thus, the CLAP can run 8 times as long as the PSAP before requiring a filter change, which is ideal for remote sites that are not visited daily.

Both the PSAPs and CLAPs use the same type of Pallflex E70-2075W filters, with the only difference being their size. As the optical designs of the two instruments are very similar, both the PSAP and CLAP data used in this study were corrected using the Bond et al. (1999) correction along with the Ogren (2010) wavelength adjustment. It has been shown before that the same type of filter and a similar optical design yields very similar results (Miyazaki et al., 2008; Nakayama et al., 2010). The Bond et al. (1999) correction includes a multiple scattering correction, a filter loading correction, and an apparent absorption correction. The apparent absorption correction makes use of light scattering coefficients (e.g. from nephelometers). At all sites in this paper where light scattering coefficients were needed to correct the PSAP and CLAP, the light scattering was measured by TSI nephelometers (TSI Inc, model 3563; Anderson and Ogren, 1998).

Although the co-located instruments are based on collecting the sample aerosol on filters, there are differences. For 
Table 2. Standard deviations of $\delta \Delta \mathrm{ATN}_{\mathrm{ND}}$ for the different Aethalometers and their measurement wavelengths. The filtered air noise measurements consist of at least $24 \mathrm{~h}$ of data, except for Alert where data was comprised of a few hours of measurements totalling 4 days. The standard deviation was calculated from subsequent reported ATN values as such and can therefore be used to reproduce Fig. 4 . The $t_{\text {avg }}$ column shows the instrument setting for the outer cycle of the instrument during the time of the noise measurements.

\begin{tabular}{|c|c|c|c|c|c|c|c|c|c|}
\hline & \multirow[t]{2}{*}{$N$} & \multirow{2}{*}{$\begin{array}{l}t_{\mathrm{avg}} \\
\min \end{array}$} & 370 & 470 & 520 & 590 & 660 & 880 & 950 \\
\hline & & & \multicolumn{7}{|c|}{$\mathrm{nm}$} \\
\hline Alert & 1267 & 5 & 0.011 & 0.010 & 0.011 & 0.010 & 0.011 & 0.008 & 0.008 \\
\hline Summit & 235 & 5 & & & & & & 0.016 & \\
\hline Barrow & 745 & 5 & 0.016 & 0.016 & 0.015 & 0.015 & 0.015 & 0.015 & 0.015 \\
\hline Tiksi & 316 & 5 & 0.007 & 0.008 & 0.006 & 0.007 & 0.007 & 0.074 & 0.004 \\
\hline Pallas & 290 & 5 & 0.003 & 0.004 & 0.003 & 0.004 & 0.003 & 0.003 & 0.004 \\
\hline Zeppelin & 48 & 30 & 0.028 & 0.012 & 0.010 & 0.031 & 0.016 & 0.012 & 0.014 \\
\hline
\end{tabular}

Table 3. Standard deviation of $\sigma_{0}\left(\delta \sigma_{0}\right)$ in $\mathrm{Mm}^{-1}$ when measuring particle-free air. These values can be used in Eq. (10) for an arbitrary value of $\sigma_{0}$ and $\Delta t$.

\begin{tabular}{lrrrrrrrr}
\hline & $\Delta t$ & $370 \mathrm{~nm}$ & $470 \mathrm{~nm}$ & $520 \mathrm{~nm}$ & $590 \mathrm{~nm}$ & $660 \mathrm{~nm}$ & $880 \mathrm{~nm}$ & $950 \mathrm{~nm}$ \\
\cline { 3 - 8 } & $\min$ & & & & $\mathrm{Mm}^{-1}$ & & & \\
\hline Alert & 5 & 0.284 & 0.251 & 0.286 & 0.253 & 0.282 & 0.215 & 0.213 \\
Summit & 5 & & & & & & 0.283 & \\
Barrow & 5 & 0.332 & 0.325 & 0.316 & 0.312 & 0.322 & 0.313 & 0.318 \\
Tiksi & 5 & 0.137 & 0.155 & 0.117 & 0.129 & 0.151 & 1.519 & 0.086 \\
Pallas & 5 & 0.136 & 0.171 & 0.144 & 0.149 & 0.111 & 0.114 & 0.156 \\
Zeppelin & 30 & 0.058 & 0.026 & 0.021 & 0.065 & 0.032 & 0.024 & 0.029 \\
\hline
\end{tabular}

aerosol particles that have a high single-scattering albedo $\left(\omega_{0}\right)$, defined as the ratio of light scattering $\left(\sigma_{\mathrm{sp}}\right)$ to light extinction $\left(\sigma_{\mathrm{ep}}\right)$, the MAAP has been shown to be less prone to interpret light scattering as light absorption than a PSAP or an Aethalometer (Petzold et al., 2005). In the Arctic, this is an advantage because of the high $\omega_{0}$ of the aerosol. Research has also shown a good agreement between the MAAP and independent reference absorption $\left(\sigma_{\mathrm{ep}}-\sigma_{\mathrm{sp}}\right)$ measurements for $\omega_{0}$ values in the range of $0.7-0.98$ (Sheridan et al., 2005). The same study also showed that the PSAP, with the Bond correction applied, agrees better with independent reference absorption measurements for atmospherically relevant $\omega_{0}$ values $(0.88)$ than for very dark aerosol $\left(\omega_{0}=0.30\right)$. At a $\omega_{0}$ of 0.88 , there was virtually no dependence of filter loading on $\sigma_{\text {ap }}$. MAAP-, PSAP-, and CLAP-derived $\sigma_{\text {ap }}$ will be cross sensitive to $\sigma_{\mathrm{sp}}$ for a purely scattering aerosol, and the extent of the cross sensitivity depends on the loading of the filter (Müller et al., 2011).

The unit to unit variability of the MAAP is comparatively lower than for the other absorption photometer instruments used in this study (Müller et al., 2011). The same study also showed that the instrument noise of the PSAP and the MAAP are lower than for Aethalometers. The design of the PSAP and CLAP instruments should also make the measured flow through the instruments less uncertain than in instruments using a filter tape roll because the filters are sealed in place inside the instrument.

It should be noted that none of the filter changes for any of the instruments can be considered to be synchronised with each other; e.g. the PSAP filter is not changed at the same time as an Aethalometer tape advance. Thus, when comparing a reference instrument to an Aethalometer, using the whole time series, any remaining cross sensitivity to the state of the filter on a reference instrument will represent the mean or median bias.

Because the reference instruments operate at different wavelengths than the Aethalometers, Angström exponents $(\alpha)$ were used to interpolate or extrapolate data to a matching wavelength; $\alpha$ were also used to match nephelometer wavelengths to reference absorption wavelengths when using the correction schemes. The Ångström exponent was calculated as follows:

$\alpha=-\frac{\log \left(\sigma_{1}\right)-\log \left(\sigma_{2}\right)}{\log \left(\lambda_{1}\right)-\log \left(\lambda_{2}\right)}$,

where $\sigma_{1}$ and $\sigma_{2}$ represent absorption or scattering coefficients at their respective wavelengths $\lambda_{1}$ and $\lambda_{2}$. Using $\alpha$, the absorption coefficient $\left(\sigma_{x}\right)$ can be calculated for a desired wavelength $\lambda_{x}$ using

$\sigma_{x}=\sigma_{1}\left(\frac{\lambda_{1}}{\lambda_{x}}\right)^{\alpha}$. 
Using Eqs. (4) and (5), the Aethalometer data was interpolated to the wavelengths 467,525 , and $637 \mathrm{~nm}$. The reference absorption instruments that did not already measure at these wavelengths were also interpolated to these three wavelengths. The 1-wavelength Aethalometer at Summit was interpolated from 880 to $637 \mathrm{~nm}$ using an $\alpha$ of 0.814 in Eq. (5).

\section{Aethalometer uncertainty analysis}

In order to investigate how the collection time approach can improve the Aethalometer measurements, the measurement uncertainties must be known. By applying the equation for the propagation of uncertainty for uncorrelated variables

$\delta \sigma_{0}=\sqrt{\sum_{i=1}^{n}\left(\frac{\partial \sigma_{0}}{\partial x_{i}}\right)^{2} \delta x_{i}^{2}}$

to Eq. (2), the relative uncertainty of the measurements can be solved. In Eq. (6), $x_{i}$ represents the independent variables - $\Delta \mathrm{ATN}, A, Q$, and $\Delta t$ of Eq. (2) - and $\delta x_{i}$ represents their uncertainties.

However, the uncertainty in $\triangle \mathrm{ATN}$ has more than one component. Therefore, prior to applying Eq. (6) to Eq. (2), the term $\triangle \mathrm{ATN}$ is decomposed into two components. The first component is the true change in $\triangle \mathrm{ATN}$ that contains no drift, here denoted as $\triangle \mathrm{ATN} \mathrm{ND}_{\mathrm{ND}}$. The second component that contributes to the uncertainty in $\triangle \mathrm{ATN}$ is drift, here denoted as $\triangle \mathrm{ATN}_{\mathrm{D}}$. Furthermore, drift can be expressed as a rate of change over the time $\Delta t$ as $k_{\mathrm{D}}=\Delta \mathrm{ATN}_{\mathrm{D}} / \Delta t$. The influence of drift for an arbitrary $\Delta t$ then becomes $k_{\mathrm{D}} \Delta t$. Thus, $\Delta$ ATN has been decomposed into $\Delta \mathrm{ATN}=\Delta \mathrm{ATN}_{\mathrm{ND}}+k_{\mathrm{D}} \Delta t$. Substituting the total change in $\Delta \mathrm{ATN}$ with $\Delta \mathrm{ATN}_{\mathrm{ND}}+k_{\mathrm{D}} \Delta t$ into Eq. (2) and applying uncertainty propagation (Eq. 6) yields after some rearrangements

$\frac{\delta \sigma_{0}}{\sigma_{0}}=\sqrt{\left(\frac{\delta A}{A}\right)^{2}+\left(\frac{\delta Q}{Q}\right)^{2}+\left(\frac{\delta \Delta \mathrm{ATN}_{\mathrm{ND}}}{\Delta \mathrm{ATN}_{\mathrm{ND}}}\right)^{2}+\left(\frac{\delta k_{\mathrm{D}}}{k_{\mathrm{D}}}\right)^{2}}$.

Note that the term $\delta \Delta t$ has been dropped here since any normal drift in the clock can be neglected.

The determination of both $\delta A$ and $\delta Q$ is to some extent dependent on the instrument operator. The term $\delta A$ can be estimated using a magnifier glass with a scale or digital image analysis to measure the area of the sample spot. Here we will assume that the filter size area can be determined with a $2 \%$ uncertainty using digital image analysis.

The value of $\delta Q$ comes from both the accuracy of the calibration and the performance of the flow controller of the instrument. The uncertainty of the flow meter (Sierra Instruments, model 824-RFQ-2430) is reported (by the manufacturer) to be $1.5 \%$, which is what will be assumed here. The flow measured by the flow meter is not the exact flow that enters the instrument since there is also a lateral flow through the fibre filter. The lateral flow will bias the internal flow me- ter readings towards higher values than the actual flow entering the system. The lateral flow is likely to be a function of the pressure difference between the sampling line and the room air, which further adds to the uncertainty in the flow rate.

The drift term $\left(\delta k_{\mathrm{D}} / k_{\mathrm{D}}\right)^{2}$ of Eq. (7) is the most demanding to assess as it may vary greatly from station to station and instrument to instrument for a number of reasons. Drift can be expected to ensue from changes in temperature or relative humidity, changes in lateral flow due to pressure changes in the sampling line, changes in semi-volatile constituents that have deposited onto the filter, etc. The sources that contribute to drift, and the impact of drift on instrument performance, are best studied under controlled conditions in a laboratory. Therefore, drift will largely be omitted in the uncertainty analysis and discussed on the basis of observations.

By substituting $\delta Q$ in Eq. (7) with the flow rate uncertainty $\left(f_{\mathrm{q}}\right)$ as a fraction of the total flow $Q$, the term $\delta Q^{2}$ becomes $\left(f_{\mathrm{q}} Q\right)^{2}$. Equivalently, if the uncertainty of the spot size area $\left(f_{\mathrm{a}}\right)$ is a fraction of the total area $A$, the term $\delta A^{2}$ becomes $\left(f_{\mathrm{a}} A\right)^{2}$. Equation (7) then becomes

$\frac{\delta \sigma_{0}}{\sigma_{0}}=\sqrt{f_{\mathrm{a}}^{2}+f_{\mathrm{q}}^{2}+\left(\frac{\delta \Delta \mathrm{ATN} \mathrm{ND}_{\mathrm{ND}}}{\Delta \mathrm{ATN})_{\mathrm{ND}}}\right)^{2}}$.

Because the drift term has been left out Eq. (8) describes the best case scenario without any drift taken into account. It should be noted that the term $\delta \Delta \mathrm{ATN}_{\mathrm{ND}}$ describes the random error that originates from the electronics in the instrument. The relative uncertainty of $\delta \Delta \mathrm{ATN}_{\mathrm{ND}} / \Delta \mathrm{ATN} \mathrm{ND}_{\mathrm{ND}}$ can be expressed in terms of measurement-derived values using particle-free air as

$\delta \Delta \mathrm{ATN}_{\mathrm{ND}, \text { air }}=\frac{Q \Delta t_{\mathrm{air}}}{A} \delta \sigma_{0, \text { air }}$.

In Eq. (9), $\delta \sigma_{0 \text {,air }}$ is the standard deviation of $\sigma_{0}$ at the time resolution of $\Delta t_{\text {air }}$. When determining $\delta \sigma_{0 \text {,air }}, \Delta t_{\text {air }}$ should be short so that $\Delta t_{\text {air }}$ is the same as the inner cycle for the Aethalometer. Similarly, $\triangle \mathrm{ATN}_{\mathrm{ND}}$ can be written as a function of $\sigma_{0}$ and substituted into Eq. (9), which yields

$$
\frac{\delta \sigma_{0}}{\sigma_{0}}=\sqrt{f_{\mathrm{a}}^{2}+f_{\mathrm{q}}^{2}+\left(\frac{\delta \sigma_{0, \text { air }} \Delta t_{\mathrm{air}}}{\sigma_{0} \Delta t}\right)^{2}} .
$$

It is often desirable to know the absolute uncertainty $\left(\delta \sigma_{0}\right)$ of the measurement in units of the quantity measured. Equation (10) then becomes

$\delta \sigma_{0}=\sqrt{\sigma_{0}^{2}\left(f_{\mathrm{a}}^{2}+f_{\mathrm{q}}^{2}\right)+\left(\frac{\delta \sigma_{0, \mathrm{air}} \Delta t_{\mathrm{air}}}{\Delta t}\right)^{2}}$.

Equation (11) implies that the absolute uncertainty of the Aethalometer scales proportionally to $\Delta t^{-1}$ when postprocessing using Eq. (2) for a fixed $\Delta \mathrm{ATN}$ and no drift; note 

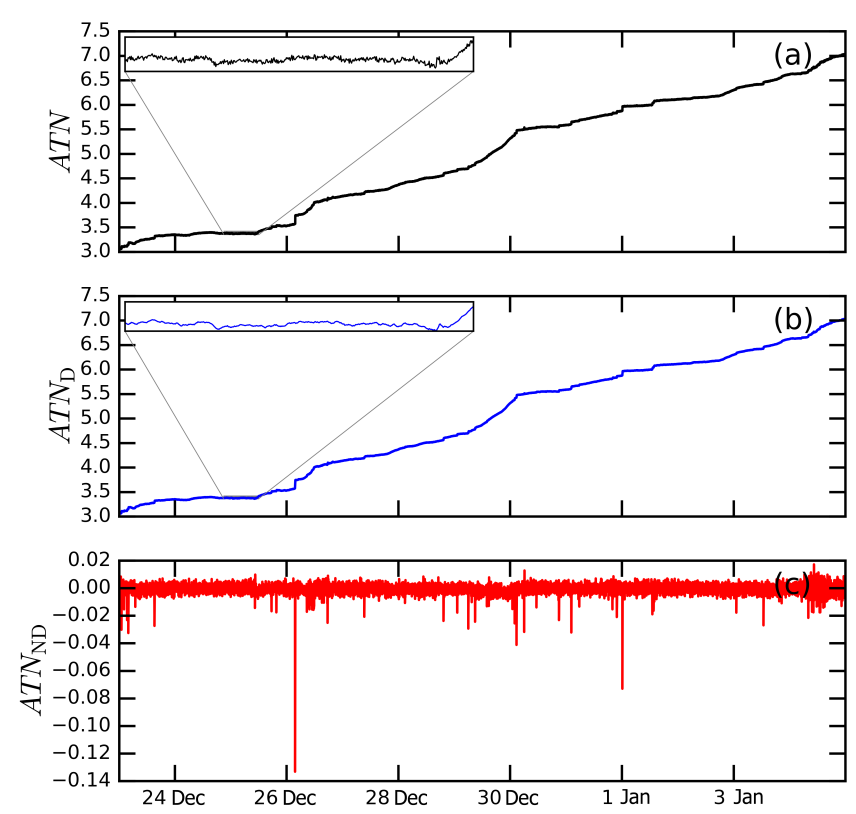

Figure 1. Decomposition of ATN from measurements of particlefree air at a wavelength of $520 \mathrm{~nm}$. Panel (a) shows the ATN values as reported by the instrument. Panel (b) shows the three-point running mean which represents the drift in ATN $\left(\mathrm{ATN}_{\mathrm{D}}\right)$. Panel (c) shows the ATN-ATND which is free of drift $\left(\mathrm{ATN}_{\mathrm{ND}}\right)$.

that $\sigma_{0}$ inside the square root contains $\Delta t^{-1}$. Solving $\delta \sigma_{0}$ from Eq. (8) yields the same conclusion.

The $\Delta t^{-1}$ dependency can be verified by measuring particle-free air. First, a time series of measurements on particle-free air is needed. This was obtained by measuring particle-free laboratory air with an absolute filter on the inlet of an Aethalometer and logging the extended format of the Aethalometer. Then, the drift in ATN was removed by subtracting a running mean of three points from the reported ATN values, yielding a time series of ATN free of $\operatorname{drift}\left(\mathrm{ATN}_{\mathrm{ND}}\right)$.

Figure 1 depicts the decomposition of ATN of laboratory measurements when measuring particle-free air through an absolute filter. From the figure, it is clear that ATN increased even though no particles should have entered the instrument because of the absolute filter connected to the sample inlet of the instrument. This test implies that there can be instrumental drift that only becomes apparent in long time series. ATN and ATN $\mathrm{ND}_{\mathrm{ND}}$ shown in Fig. 1a and 1c constitute the data used to produce Fig. 2 in addition to the eBC data that was used for the boxcar average $t_{\text {avg }}$ in the figure. Figure $1 \mathrm{c}$ also strengthens the argument that the term $\delta \Delta \mathrm{ATN}_{\mathrm{ND}}$ is close to the random error from the electronics when using a running mean to derive $\triangle \mathrm{ATN}_{\mathrm{ND}}$ from ATN.

The origin of the drift is not evident and there can well be more than one source for the observed drift. The sampling line comprised a short tube connecting a low resistance absolute filter and a flow meter to the instrument which was open

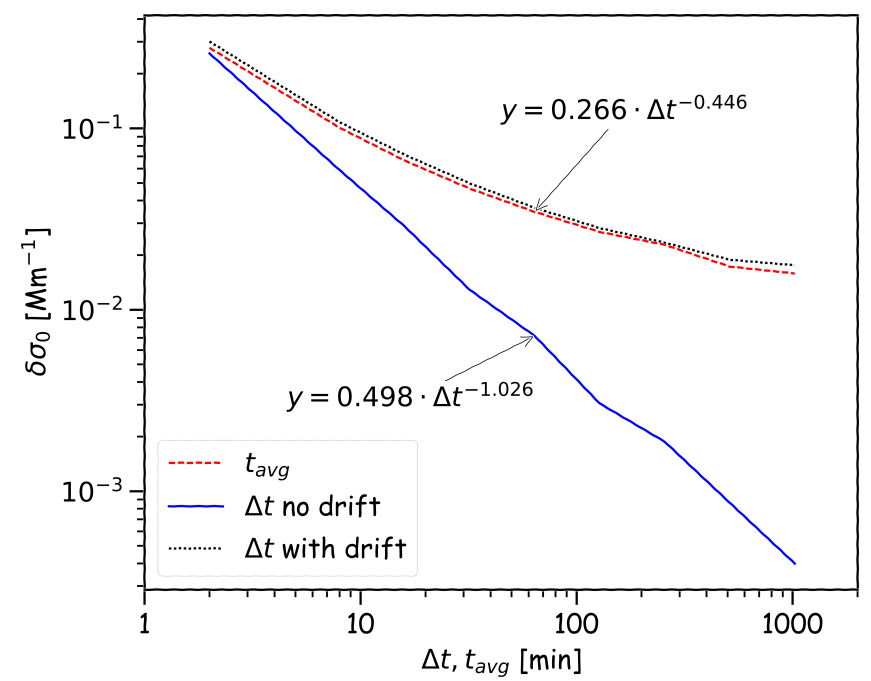

Figure 2. Standard deviation of attenuation coefficients $\left(\delta \sigma_{0}\right)$ when measuring particle-free air as a function of collection time $(\Delta t)$ with drift and without drift in the data. The $t_{\text {avg }}$ curve is calculated from eBC data as reported by the instrument and converted to $\sigma_{0}$ using a $\mathrm{MAC}_{\mathrm{AE}}$ of $28.13 \mathrm{~m}^{2} \mathrm{~g}^{-1}$. The wavelength used to produce the figure is $520 \mathrm{~nm}$.

to laboratory air in the other end. The low resistance absolute filter, and the moderate flow rate, should only lower the pressure in the sampling line minutely. If this pressure drop were the reason that unfiltered air enters the sampling line after the filter causing drift, then the drift should be greater when the instrument is connected to a high-volume inlet at a measurement station.

However, the flow was a constant $3.87 \pm 0.02$ litres per minute $\left(\mathrm{L} \mathrm{min}^{-1}\right)$, and the room temperature was a constant $23.2 \pm 0.3^{\circ} \mathrm{C}$ (mean \pm standard deviation). Fluctuations in the flow rate and room temperature did not coincide with clear changes in ATN, thus not supporting a pressure difference nor a temperature drift hypothesis, at least not directly. A time series of all wavelengths of ATN, flow rate, and room temperature is shown in Fig. A1 in Appendix A. The times when the most visible jumps occurred were close to midnight on 26 December and 1 January when there was no activity in the lab. The timing of the abrupt changes suggests that unintentional human interference is not likely. Involuntary movement of the filter could well cause an ATN change; but that it occurs by itself seems very unlikely but not impossible.

A hypothesis that could contribute to the observed drift is the adsorption of semi-volatile organic compounds onto the filter. The possible adsorption of organics with an absolute filter in front would likely be severely hampered in comparison to what the effect would be without the filter because of adsorption in the absolute filter. The absorption Ångström exponent ( $\alpha_{\text {ap }}$, see Eq. 4 ) of $\sigma_{0}$ during the measurements was 1.29. As the origin of the ATN drift is unclear, so is the meaning of $\alpha_{\mathrm{ap}}$. Furthermore, it is likely that changes in relative 
humidity will cause ATN to fluctuate, but this is unlikely to cause the steady increase in ATN as seen in Fig. 1.

The ATN $\mathrm{ND}_{\mathrm{ND}}$ of Fig. 1 was used to calculate $\Delta \mathrm{ATN}_{\mathrm{ND}}$ (and $\Delta$ ATN) for a range of $\Delta t$ values $(2,8,16,32 \ldots 1024 \mathrm{~min})$ to produce new time series of $\sigma_{0}$ using Eq. (2). From these time series, the standard deviation of $\sigma_{0}$ was calculated and plotted as a function of $\Delta t$ as shown in Fig. 2. The time series used comprised 13 days of measurements with a $\Delta t$ of $2 \mathrm{~min}$. Consequently, the values used to calculate $\delta \sigma_{0}$ in the figure decreased with increasing $\Delta t$.

Figure 2 shows that when the drift is removed the absolute uncertainty $\delta \sigma_{0}$ follows the predicted $\Delta t^{-1}$ relationship. The curve fit for the drift-free $\delta \sigma_{0}$ as a function of $\Delta t$ gives a slope of -1.026; see Fig. 2. When the drift is not removed, using the running mean method described before, $\delta \sigma_{0}$ is not reduced nearly as rapidly as for the non-drift situation. The difference is arguably due to drift. Also shown in the figure is $\delta \sigma_{0}$ of boxcar-averaged $\sigma_{0}$ converted from the eBC output of the instrument as $\sigma_{0}=\mathrm{MAC}_{\mathrm{AE}} \cdot \mathrm{eBC}$. The same time interval was used for boxcar averaging $\left(t_{\mathrm{avg}}\right)$ as was used for $\Delta t$.

\section{Measurement results}

\subsection{Measured uncertainties}

Aethalometers that are deployed in clean environments can appear at times to just be reporting noise. By simple data post-processing, the signal can be extracted with a greater accuracy, albeit at the expense of temporal resolution (Hagler et al., 2011). This can be done by allowing for a temporal resolution that matches the concentration of species that creates the instrument response, namely the change in ATN, by choosing a constant relative uncertainty (Eq. 8). Equation (8) states that when $f_{\mathrm{q}}$ and $f_{\mathrm{a}}$ are constant, the relative uncertainty depends on the change in filter attenuation $\left(\triangle \mathrm{ATN}_{\mathrm{ND}}\right)$. This fact can be used to produce a time series with a constant relative uncertainty.

However, it should be acknowledged that there is an additional uncertainty due to instrument drift, but in principle a constant uncertainty could also be achieved using Eq. (7). That would require a thorough investigation into the sources for the drift and how they vary between stations, which is not feasible in this study given the remote locations of the stations. However, based on the laboratory measurements the drift can be significant on a timescale from hours to days. When the aim is to determine the drift at a station, the absolute filter should be attached to the sampling line to capture the pressure changes in the sampling line relative to ambient pressure, and changes in relative humidity, on a pristine filter. This could possibly be extended to include loaded filters for different aerosol types and filter loadings.

The measurement uncertainties for the six Aethalometers at the respective stations were determined by measuring particle-free air. For all stations except Alert, particle-

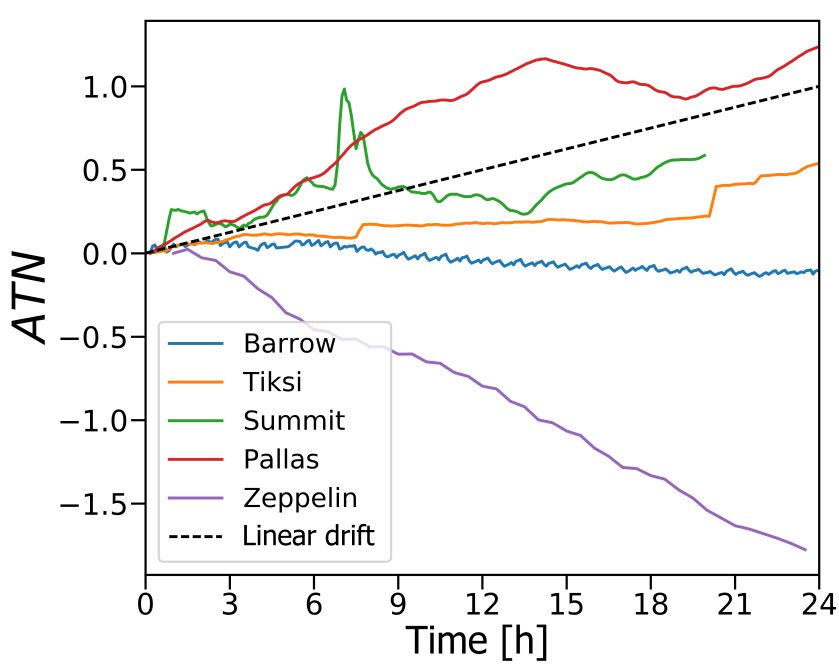

Figure 3. Drift in ATN during measurements of particle-free air at five arctic stations. The linear drift shown in the figure corresponds to a $\sigma_{0}$ value of $0.07 \mathrm{Mm}^{-1}$ when $Q=5 \mathrm{~L} \mathrm{~min}^{-1}, A=0.5 \mathrm{~cm}^{2}$, and the drift in ATN is 1 in $24 \mathrm{~h}$. In the figure, ATN has been forced to begin at 0 for easier comparison; see Appendix A for greater detail.

free air was sampled for at least $24 \mathrm{~h}$ with an absolute filter connected to the instrument inlet. These measurements are shown in Fig. 3 at a wavelength of $590 \mathrm{~nm}$ (Summit $880 \mathrm{~nm}$ ). For Alert, the particle-free air was sampled for a few hours per week comprising 4 days of data in total.

Figure 3 depicts the ATN drift in the different Aethalometers during the particle-free air measurements. The figure shows that all the tested Aethalometers experienced drift during the particle-free air measurements. Also evident from the figure is that the drift of the different Aethalometers (and different sites) can differ. Based on the figure, it is not enough to conduct measurements on particle-free air for a few hours in order to assess the instrument performance at the site. Filtered air measurements should instead be performed over a period of $24 \mathrm{~h}$ or more. These measurements should be conducted on a pristine filter to minimise the influence of semivolatile constituents that could have been deposited onto the filter (Cappa et al., 2008; Lack et al., 2008).

For reference, a linear drift of $\Delta \mathrm{ATN}_{\mathrm{D}}=1.0$ in $24 \mathrm{~h}$ is shown in Fig. 3, which corresponds to a $\sigma_{0}$ value of $0.07 \mathrm{Mm}^{-1}$ when using $Q=5 \mathrm{~L} \mathrm{~min}^{-1}, A=0.5 \mathrm{~cm}^{2}$, and $\Delta t=24 \mathrm{~h}$. The consequence of a linear drift of 1.0 in $24 \mathrm{~h}$ would also set the lowest value achievable. As can be seen from the inserts of Fig. 1, ATN $N_{D}$ needs not be increasing all the time, and thus lower values of $\sigma_{0}$ are achievable during periods with little drift. It should be mentioned that this drift will also affect the $\mathrm{eBC}$ concentrations reported by the instrument. For the five instruments evaluated here, the drift uncertainty is shown in Fig. 3 to be roughly $0.01-0.1 \mathrm{Mm}^{-1}$. 
The particle-free air measurements were not all conducted in the same manner, which is both fortunate and unfortunate. Figure A2 in Appendix A shows the zero air measurements for ATN in greater detail. The Aethalometers at Alert, Barrow, Tiksi, and Pallas were not connected to the common aerosol inlet at the sites but drew air from inside, through a low resistance absolute filter. Again, this setup should only result in a negligible lower pressure in the sampling line after the filter. The most intriguing of the zero air measurements is Tiksi. Similar to Fig. 1, Tiksi shows abrupt changes in ATN that cannot be related to pressure changes in the sampling line. One of the abrupt changes occurred at night when there was no personnel at the station (see Fig. A2). The Tiksi Aethalometer also shows uneven drift, when compared to other channels, for the 370 and $950 \mathrm{~nm}$ channels that cannot be explained with aerosol deposition onto the filter. The hypothesis is therefore that this is electronic drift. Changes in filter morphology or position should affect all wavelengths. The Tiksi Aethalometer also has a noisy $880 \mathrm{~nm}$ channel which is clearly visible in Fig. A2.

Pallas, Zeppelin, and Summit all experienced drift immediately following the change to a pristine filter although the drifts were quite different. For Pallas, the drift was observed as a gradual and increasing ATN. The drift was largest for $370 \mathrm{~nm}$ at both Pallas and Zeppelin but not in the same very clear trend breaking way that was observed at Tiksi; although at Zeppelin the $370 \mathrm{~nm}$ channel behaved somewhat differently than the other channels. At Summit, the ATN changes were faster although smaller in magnitude. Again we hypothesise that these changes in ATN during the particle-free air measurements can be due to deposition or evaporation, or both, of semi-volatile organic compounds or changes in sample air relative humidity. The decreasing ATN at Zeppelin could be due to evaporation of adsorbed water or organics from the filter. At Barrow, the zero air measurements were conducted on a loaded filter. After an absolute filter was placed before the instrument, ATN started to drop. Possible causes can be the evaporation of organics or water vapour. It is possible that the absolute filter changes the partial pressure of one or more gas-phase constituents that subsequently affect the ATN. The rapid changes in the Barrow ATN values correlate well with rapid fluctuations in the sampling line temperature which is exposed to room air and therefore also to the air-conditioning unit. The ATN values increased when room temperature was dropped and vice versa.

The standard deviations of the $\triangle \mathrm{ATN}_{\mathrm{ND}}$ measurements made with an absolute filter in line are shown in Table 2. Because the only wavelength-dependent variable in Eq. (8) is $\delta \triangle \mathrm{ATN}_{\mathrm{ND}}$, the change in the $\triangle \mathrm{ATN}$ measurements with respect to wavelength will also be the sole source of the difference in the relative uncertainty between different wavelengths. The values that describe the relative uncertainty in terms of $\Delta t$ and $\sigma_{0}$ (Eq. 10) are presented in Table 3.

Figure 4 shows the relative uncertainty $\left(\delta \sigma_{0} / \sigma_{0}\right)$ of Eq. (8) as a function of $\triangle \mathrm{ATN}_{\mathrm{ND}}$ based on measurements conducted

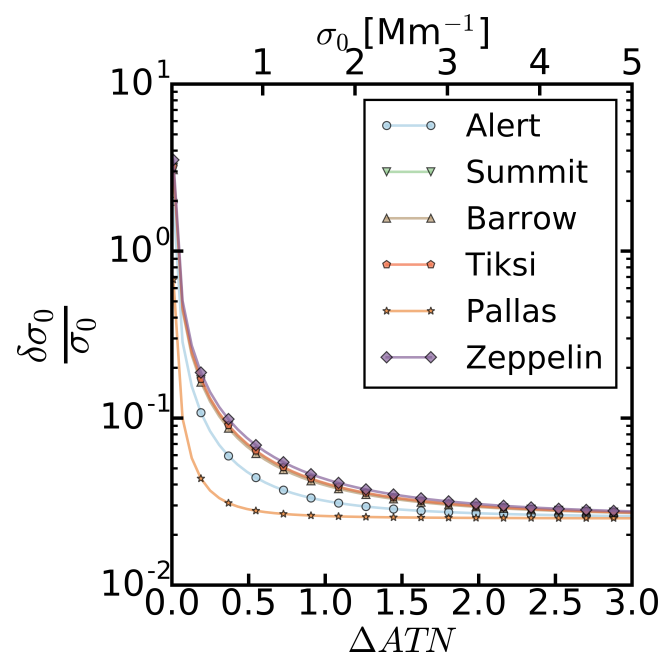

Figure 4. Relative uncertainty of attenuation coefficients as a function of change in filter attenuation $(\triangle \mathrm{ATN})$; see Eq. (7). The upper $x$ scale was calculated using $A=0.5 \mathrm{~cm}^{-2}, Q=5 \mathrm{~L} \mathrm{~min}^{-1}$ and $\Delta t=60 \mathrm{~min}$ for reference.

with an absolute filter upstream of the instrument. For clarity, the figure was produced using a mean of all wavelengths to represent the typical relative uncertainty of the instrument. The mean values were calculated from Table 2. Figure 4 shows how the relative uncertainty decreases when $\triangle$ ATN increases. The upper $x$-axis scale of $\sigma_{0}$ in the figure was calculated for reference using $Q=5 \mathrm{~L} \mathrm{~min}^{-1}, A=0.5 \mathrm{~cm}^{2}$, and $\Delta t=60 \mathrm{~min}$.

Implicit from both Fig. 4 and Eq. (8) is that the relative uncertainty of the instrument changes with the aerosol concentration when using a fixed $\Delta t$; for a fixed $\Delta t, \Delta \mathrm{ATN}$ will change according to the concentration. The equation for the relative uncertainty (Eq. 8) can be used as a criterion to achieve a more constant level of uncertainty which was not captured when the method was introduced by Hagler et al. (2011). This can either be determined from Fig. 4 directly or calculated from Eq. (8) after the term $\delta \Delta \mathrm{ATN}_{\mathrm{ND}}$ has been determined.

One way to characterise the performance of an Aethalometer is to calculate the $\triangle \mathrm{ATN}$ value at which the flow $\left(f_{\mathrm{q}}\right)$ and spot size $\left(f_{\mathrm{a}}\right)$ uncertainties together are equally important as the $\triangle$ ATN uncertainties. This is shown in Table 4. The crossover was calculated by solving $\triangle \mathrm{ATN}$ from the terms under the square root of Eq. (8), namely $\triangle \mathrm{ATN}_{\mathrm{ND}}=$ $\left(\delta \Delta \mathrm{ATN}_{\mathrm{ND}}^{2} /\left(f_{\mathrm{a}}^{2}+f_{\mathrm{q}}^{2}\right)^{2}\right)^{1 / 2}$. The uncertainty in the flow rate, relative to the uncertainty in the ATN measurements, diminishes exponentially when $\triangle \mathrm{ATN}$ decreases (Fig. 4). Here, a criterion of $\triangle \mathrm{ATN} \geq 2$ was used in the post-processing of the data to also allow for a lower detection limit in the boxcaraveraged reference data that is discussed in the next section.

For the sake of simplicity, this criterion was only applied to the middle wavelength of the Aethalometer $(590 \mathrm{~nm})$. If the criterion were to be applied to all wavelengths, one would 
Table 4. Crossover $\triangle \mathrm{ATN}$ above which the flow rate uncertainty $\left(f_{\mathrm{q}}=1.5 \%\right)$ and spot size uncertainty $\left(f_{\mathrm{a}}=2.0 \%\right)$ together become more important than $\delta \Delta \mathrm{ATN}_{\mathrm{ND}}$.

\begin{tabular}{lrrrrrrr}
\hline & $370 \mathrm{~nm}$ & $470 \mathrm{~nm}$ & $520 \mathrm{~nm}$ & $590 \mathrm{~nm}$ & $660 \mathrm{~nm}$ & $880 \mathrm{~nm}$ & $950 \mathrm{~nm}$ \\
\hline Alert & 0.87 & 0.77 & 0.87 & 0.77 & 0.86 & 0.65 & 0.65 \\
Summit & & & & & & 1.27 & \\
Barrow & 1.27 & 1.25 & 1.21 & 1.19 & 1.24 & 1.20 & 1.22 \\
Tiksi & 0.54 & 0.61 & 0.46 & 0.51 & 0.59 & 5.96 & 0.34 \\
Pallas & 0.26 & 0.33 & 0.28 & 0.29 & 0.21 & 0.22 & 0.30 \\
Zeppelin & 2.23 & 1.00 & 0.82 & 2.49 & 1.25 & 0.94 & 1.11 \\
\hline
\end{tabular}

end up with seven time series for each instrument, with different timestamps. That could make further data analysis unnecessarily convoluted. It is worth pointing out that if the data set being analysed is going to be averaged, then the ATN values included with the averaged data set should not be averaged - an averaged ATN would make $\Delta t$ less well defined. Instead, either the first or the last ATN value during the averaging period should be incorporated into the averaged data set.

The time series of the $1 \mathrm{~h}$ boxcar-averaged Aethalometer data is show in Fig. 5. The time series of the adaptive collection time is shown in Fig. 6. When using the adaptive collection time, it is clear that when the absorption coefficient is low, the time resolution is low. At higher absorption coefficients, the time resolution is better. This is desirable since it means that at high concentrations of light absorbing aerosol particles there is no loss in temporal resolution, whereas at low concentrations this adaptive method is capable of reaching lower detection limits quicker than boxcar averaging when drift is minimal.

Comparing Figs. 5 and 6 , it is clear that the adaptive collection time approach is to be favoured when $\sigma_{\text {ap }}<$ $0.1 \mathrm{Mm}^{-1}$ because of instrument noise. In Fig. 5, it is shown that at low $\sigma_{\text {ap }}$ the $1 \mathrm{~h}$ averages of the data set are clearly more scattered than when using the adaptive collection time method when $\sigma_{\text {ap }}$ is low (Fig. 6). Since the $y$-scale of Fig. 5 is logarithmic, negative values are not shown, although they are still present in the $1 \mathrm{~h}$ averaged time series. By definition, the adaptive collection time approach will not produce negative $\sigma_{0}$ values since $\triangle \mathrm{ATN}$ is always positive.

In fact, for the measurements studied here, when the $\sigma_{0}$ is above $2.1-6.7 \mathrm{Mm}^{-1}$, there is no loss in the temporal resolution in the $1 \mathrm{~h}$ averaged data of Fig. 5. The range in $\sigma_{0}$ is due to the fact that the different Aethalometers at these six Arctic sites are operated at different flow rates. Figure 7 shows histograms of $\Delta t$ for the different stations using the adaptive collection time approach.

Figure 6 shows values that are lower than the example drift in $\triangle \mathrm{ATN}=1.0$ in $24 \mathrm{~h}$ (Fig. 3), which implies that there are periods where the drift can be substantially lower. In Figs. 5 and 6 , the $\sigma_{\text {ap }}$ values come from $\sigma_{0}$ values that have been corrected using a $C_{\mathrm{f}}$ value of 3.45 as discussed in the next section. Thus, the drift uncertainty seen in Fig. 3 becomes $0.003-0.03 \mathrm{Mm}^{-1}$ after $C_{\mathrm{f}}$ is applied.

\subsection{Aethalometer correction factor for the Arctic}

The determination of the Aethalometer correction factor for the Arctic was done according to Eq. (3). For the calculations, $\sigma_{0}$ values were obtained using the collection time approach because a constant relative uncertainty is desirable. The collection time approach applied to the Aethalometer data impacts the co-located absorption photometer data as well. The collection times for the Aethalometers were adapted to $\triangle$ ATN. Subsequently, data from the co-located instruments were boxcar-averaged to the same time intervals as the Aethalometer data in order to calculate $C_{\mathrm{f}}$. The co-located instruments will therefore have a longer averaging during times when $\sigma_{\mathrm{ap}}$ is low, given that $\sigma_{\mathrm{ap}}$ and $\Delta \mathrm{ATN}$ correlate. For standard boxcar averaging, random measurement noise reduces proportionally to $t_{\mathrm{avg}}^{-0.5}$ (e.g. Springston and Sedlacek, 2007). Using the collection time approach, $\delta \sigma_{0}$ can at best be reduced at a rate of $\Delta t^{-1.0}$ (Fig. 2).

Applying uncertainty propagation on Eq. (3) yields

$\frac{\delta C_{\mathrm{f}}}{C_{\mathrm{f}}}=\sqrt{\left(\frac{\delta \sigma_{0}}{\sigma_{0}}\right)^{2}+\left(\frac{\delta \sigma_{\mathrm{ap}}}{\sigma_{\mathrm{ap}}}\right)^{2}}$.

The term $\delta \sigma_{0} / \sigma_{0}$ is discussed in this work and cannot be lower than the spot sizes and flow rate uncertainties. This also holds true for the co-located absorption photometers. Equation (12) also implies that the relative uncertainty of $C_{\mathrm{f}}$ increases when $\sigma_{\text {ap }}$ and $\sigma_{0}$ are low if the absolute uncertainties $\delta \sigma_{\mathrm{ap}}$ and $\delta \sigma_{0}$ remain constant. Using $\Delta \mathrm{ATN}$ to determine the averaging time for $\sigma_{\mathrm{ap}}$ will lower $\delta \sigma_{\mathrm{ap}}$ proportionally to $t_{\mathrm{avg}}^{-0.5}$. For non-drift situations, the adaptive collection time approach will reduce $\delta \sigma_{0}$ at a rate of $\Delta t^{-1.0}$, which is faster than boxcar averaging and desirable because Aethalometers are generally more noisy than PSAPs and MAAPs. For reference, the PSAP and MAAP absolute uncertainties are typically 0.02 and $0.06 \mathrm{Mm}^{-1}$ for $5 \mathrm{~min}$ averages (Müller et al., 2011). The 5 min PSAP absolute uncertainty was calculated from $0.05 \mathrm{Mm}^{-1}$ for $1 \mathrm{~min}$ averages using a $t_{\text {avg }}^{-0.5}$ dependency. These absolute uncertainties of the PSAP and MAAP 


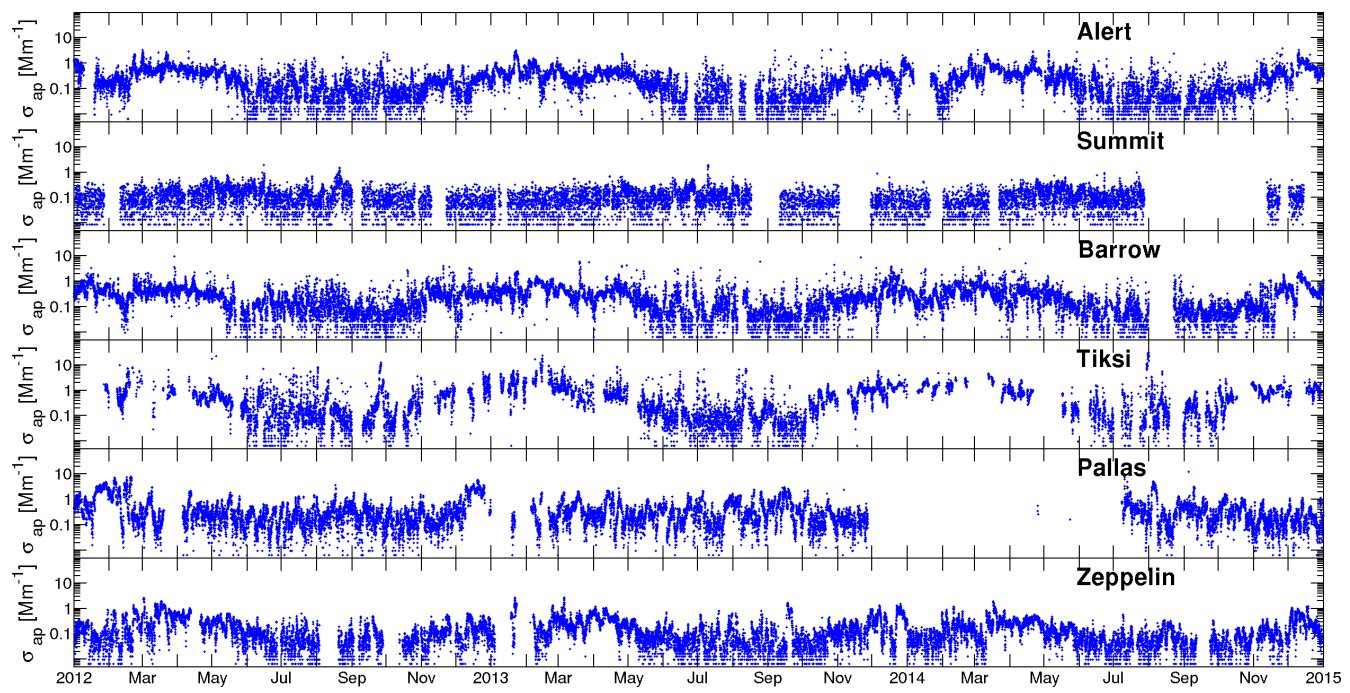

Figure 5. Time series of $1 \mathrm{~h}$ averaged absorption data for $\lambda=520 \mathrm{~nm}$. In the figure, the attenuation coefficients have been corrected using the Arctic correction factor $C_{\mathrm{f}}$ of 3.45 .

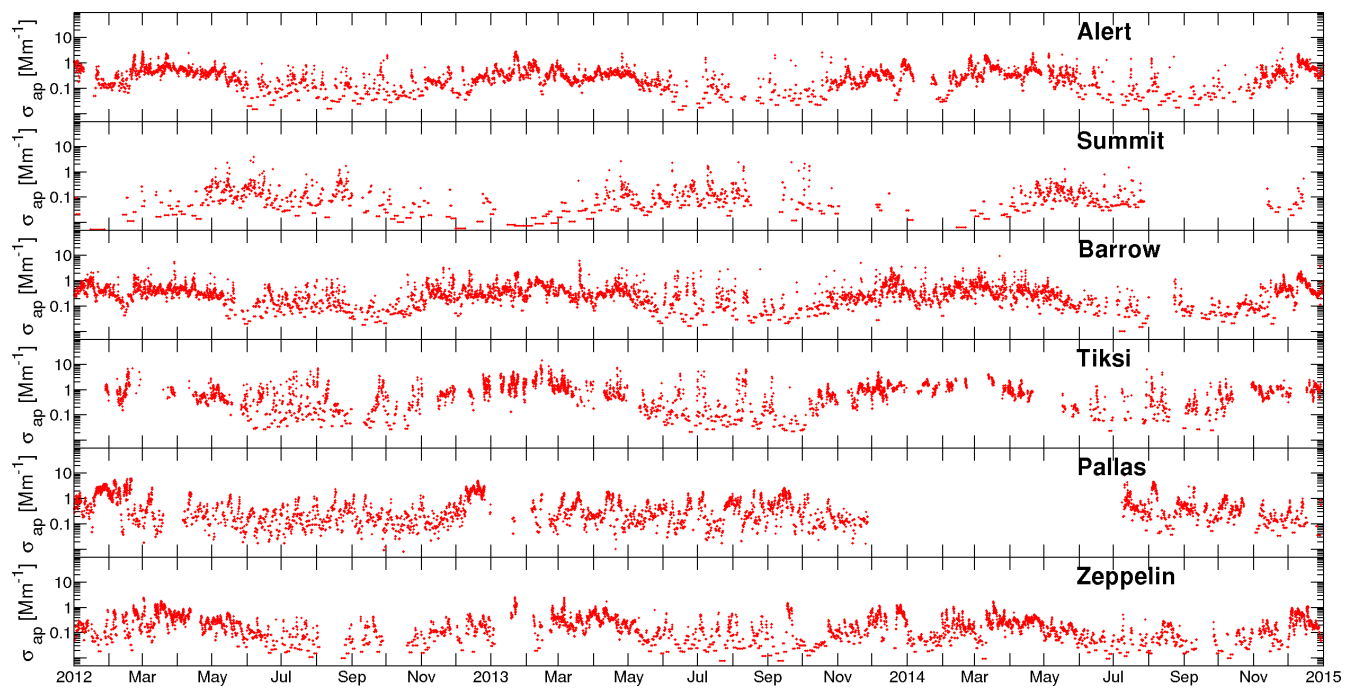

Figure 6. Time series of absorption coefficients using the adaptive collection time approach at a wavelength of $520 \mathrm{~nm}$. The attenuation coefficients have been corrected using the Arctic correction factor $C_{\mathrm{f}}$ of 3.45 .

are much lower than the Aethalometer uncertainties shown in Table 3.

The uncertainty of $C_{\mathrm{f}}$ is greater than the uncertainty that originates in measurement noise. Filter-based absorption photometers are generally considered to be accurate to within $20-30 \%$ of the true $\sigma_{\text {ap }}$ value (Bond et al., 2013). The accuracy is a combination of electronic noise, instrument variability, and calibration uncertainty (e.g. Sherman et al., 2015). The adaptive averaging time approach will only lower measurement uncertainties from electronic noise and not the uncertainties associated with the measurement technique itself.

The $C_{\mathrm{f}}$ values presented here can be used in many of the existing Aethalometer correction algorithms in the place of the multiple scattering enhancement factor. However, $C_{\mathrm{f}}$ values calculated here should be viewed as a harmonising correction factor for the Arctic Aethalometers to the co-located filter-based absorption photometers and not as a literal multiple scattering enhancement factor.

There are several possible issues with the derivation of $C_{\mathrm{f}}$ values presented here. First, in this study, the co-located absorption photometers also rely on measurements using filterbased absorption techniques - it remains unclear to which extent this will affect the absolute values of $C_{\mathrm{f}}$ because no absorption standard measurements were available at the sites. However, since the filter changes of the different instruments are not synchronised, and because the data sets cover 3 years 

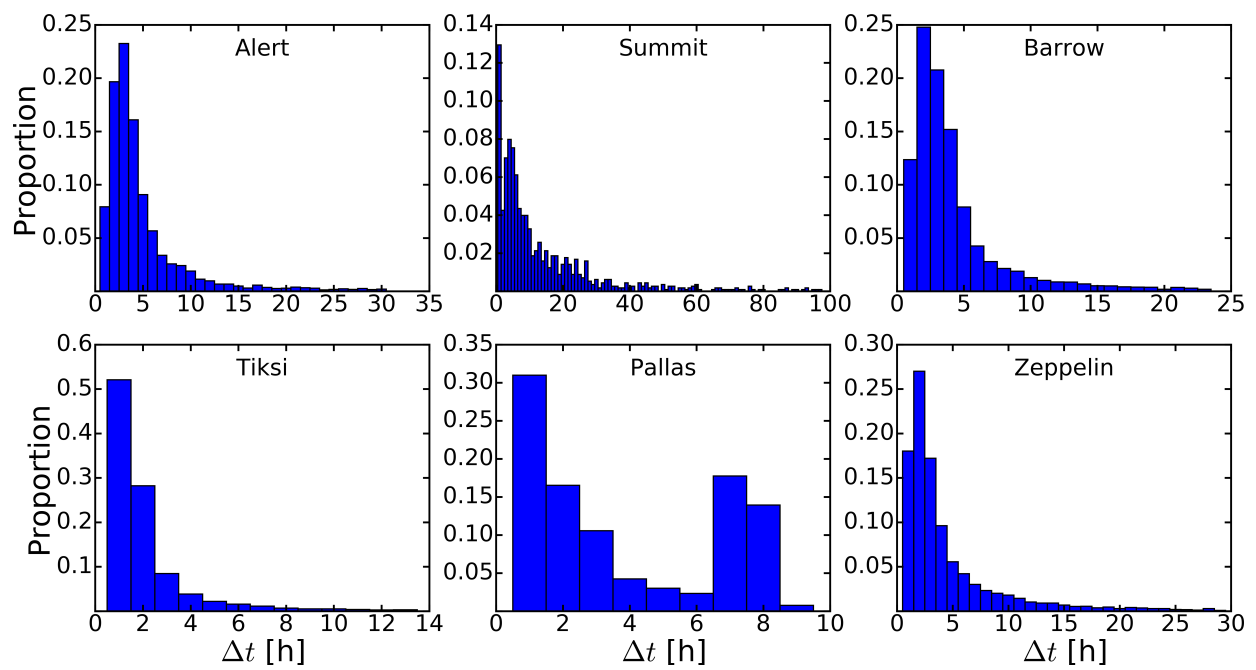

Figure 7. Normalized histogram of the collection time $\Delta t$ for the different stations for a $\Delta$ ATN threshold of 2 .

at each site, it can be assumed that there is very little coincidence with respect to filter loading effects. Thus, the $C_{\mathrm{f}}$ values presented here should represent typical values for the different sites. This argumentation should especially hold true for a moderately loaded filter, e.g. ATN $<10$. Second, the flow rates of the different instruments differ, which can affect the $C_{\mathrm{f}}$ values due to different penetration depths (Lack et al., 2009; Nakayama et al., 2010). Third, it has to be acknowledged that there can be a bias in the absolute $C_{\mathrm{f}}$ values because of imperfect corrections of filter artefacts in the reference instruments (Backman et al., 2014; Müller et al., 2011). However, this bias should not fundamentally alter the ATN dependency because filter changes were not performed in sync. The reasoning is elaborated on in Appendix B. As the filter gets loaded with aerosol particles, loading effects come into play. These loading effects change between the filter spots depending on the optical properties of the aerosol that is being deposited on that particular spot (Virkkula et al., 2015) and even during sampling on the same spot (Drinovec et al., 2015).

Such detailed analysis of filter loading effects is not feasible with this data set since it would require data with a high temporal resolution and preferably concurrent nonfilter-based light absorption measurements. In general, the goodness of evaluation for all filter-based light absorption measurements should be the continuous light absorption coefficients over filter spot changes so that a filter spot change would go unnoticed; this should hold true for all aerosol types and loadings. This means that there would not be an ATN dependency when compared to non-filter-based light absorption measurements.

It has been shown that published Aethalometer correction algorithms, which aim to compensate for filter loading and multiple scattering effects, do not necessarily remove the ATN dependence when applied on data from different sta- tions (Fig. 4 in Collaud Coen et al., 2010). Again, the aim is not to add another correction algorithm to literature. Instead, the $C_{\mathrm{f}}$ values presented here should be interpreted as a means to make Aethalometers in the Arctic more inter-comparable by introducing a $C_{\mathrm{f}}$ value for the Arctic using the co-located absorption photometers.

Figure 8 shows the calculated $C_{\mathrm{f}}$ values as a function of ATN for the six Arctic sites. Since the data depicted in Fig. 8 were produced using a concentration-adapted collection time, the statistics in the figure were calculated using a collection-time-weighted percentile (Hyndman and Fan, 1996). Without this weighting, the statistics would have effectively been concentration weighted. Figure 8 is equivalent to Fig. 4 of Collaud Coen et al. (2010) for the values labelled "AE manufacturer" in their figure.

In general, Tiksi and Pallas show the highest $C_{\mathrm{f}}$ values, whereas Summit shows the lowest. Summit stands out as an outlier in Fig. 8; it is the station at the highest elevation and uses a 1-wavelength Aethalometer $(880 \mathrm{~nm})$. The Summit Aethalometer data were interpolated to a wavelength of $637 \mathrm{~nm}$ using an $\alpha$ of 0.814 obtained from the co-located 3wavelength CLAP. A summary of the different $C_{\mathrm{f}}$ values calculated for the stations is presented in Table 5.

In addition to the different $C_{\mathrm{f}}$ values observed over the ATN range in Fig. 8, there are other differences among the stations. Some of the $C_{\mathrm{f}}$ values decrease as a function of ATN. In the ATN range of $0-10$, the median $C_{\mathrm{f}}$ values for Alert and Tiksi are greater than at the other stations, but at higher ATN the Alert and Tiksi $C_{\mathrm{f}}$ values decrease. This is an expected behaviour and is due to the filter loading effect causing a decrease in Aethalometer sensitivity. However, a decrease in $C_{\mathrm{f}}$ with ATN is barely noticeable for the Barrow and Zeppelin data sets, although the variation in $C_{\mathrm{f}}$ at Zeppelin makes the trend - or lack thereof - less clear. 

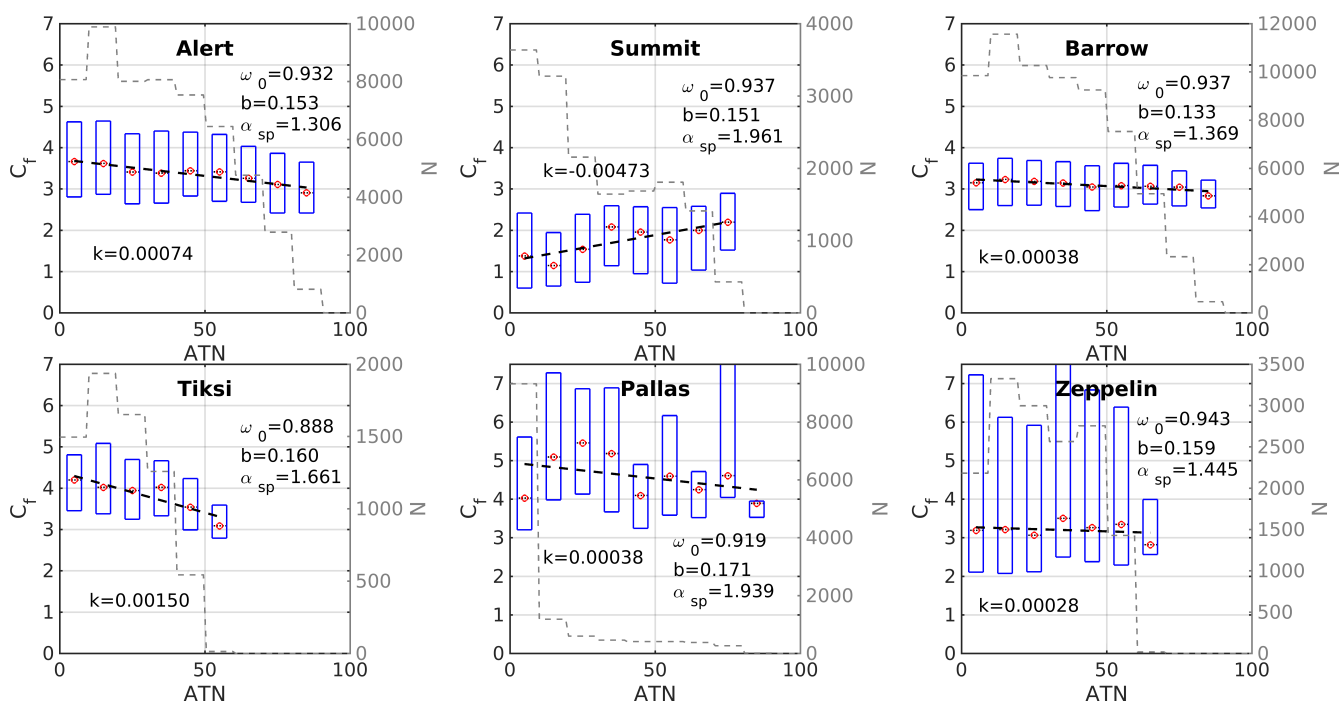

Figure 8. Correction factor $\left(C_{\mathrm{f}}\right)$ as a function of filter attenuation (ATN) calculated using Eq. (3). The grey dashed line and the right hand $y$ axis show the number of data points that each ATN range comprise. The blue boxes represent the 25 th to 75 th percentile range, whereas the red circles represent the median values. $C_{\mathrm{f}}$ values in the figure are for all available wavelengths. The figure also shows the median singlescattering albedo $\left(\omega_{0}\right)$, back-scatter fraction $(b)$, and scattering Ångström exponents $\left(\alpha_{\mathrm{sp}}\right)$. The $\omega_{0}$ of the aerosol was calculated using the absorption coefficients from Fig. 6. The slope of the ATN dependence is shown as the value $k$ so that $C_{\mathrm{f}}^{-1}=\sigma_{\mathrm{ap}} / \sigma_{0}=1+k \cdot$ ATN .

Table 5. Aethalometer correction factors $\left(C_{\mathrm{f}}\right)$ for the different stations. The values were calculated using averaging-time-weighted percentiles because of the adaptive average time used to derive them. The top portion of the table reports the $C_{\mathrm{f}}$ values for all available wavelengths of the co-located absorption instruments. Aethalometer wavelengths were interpolated to these co-located absorption photometer wavelengths using absorption Ångström exponents. The Summit AE-16 data were extrapolated to a wavelength of $637 \mathrm{~nm}$ using $\alpha=0.814$. The bottom portion of the table reports the statistics of $C_{\mathrm{f}}$ using all available wavelengths. The last row in the table shows the number of data points $(N)$ used for the statistics. The overall statistics comprise all stations except the high-altitude station of Summit.

\begin{tabular}{lcrrrrrr}
\hline & Alert & Summit & Barrow & Tiksi & Pallas & Zeppelin & Overall \\
\hline \multicolumn{7}{c}{$C_{\mathrm{f}}$ for individual wavelengths } \\
\hline $467 \mathrm{~nm}$ & 3.43 & - & 3.17 & - & - & - & - \\
$525 \mathrm{~nm}$ & 3.43 & - & 3.09 & - & - & 3.25 & - \\
$637 \mathrm{~nm}$ & 3.43 & 1.61 & 3.12 & 4.01 & 4.22 & - & - \\
\hline \multicolumn{7}{c}{ Percentile values of $C_{\mathrm{f}}$ (all wavelengths) } \\
\hline 25th & 2.70 & 0.73 & 2.56 & 3.34 & 3.36 & 2.28 & 2.93 \\
50 th & 3.43 & 1.61 & 3.12 & 4.01 & 4.22 & 3.25 & 3.45 \\
75 th & 4.37 & 2.44 & 3.64 & 4.77 & 5.85 & 6.91 & 4.15 \\
$N$ & 3455 & 1055 & 3590 & 2348 & 3226 & 2836 & 16510 \\
\hline
\end{tabular}

Again, Summit shows a different behaviour altogether. As the filter ATN increases, so do the $C_{\mathrm{f}}$ values. This is contrary to the expected behaviour of the filter loading effect in which loading generally decreases the sensitivity of a filter-based absorption measurement technique (Arnott et al., 2005; Virkkula et al., 2007). The filter loading effect is most pronounced for an aerosol with a low $\omega_{0}$ (Sheridan et al., 2005). The fact that Summit does not follow this trend suggests that the aerosol optical properties of Summit are different in relation to the other stations. The different be- haviour, however, does not seem to be related to $\omega_{0}$ as the $\omega_{0}$ of Summit does not stand out.

The scattering Ångström exponent ( $\alpha_{\text {sp }}$, Eq. 4) is shown in Fig. 8. The $\alpha_{\mathrm{sp}}$ of an aerosol is indicative of aerosol particle size with values below unity indicating super micron aerosol, and values close to 4 indicate a predominantly finemode aerosol. Only the nephelometers at Pallas and Summit are connected to $\mathrm{PM}_{2.5}$ inlets, with the rest connected to $\mathrm{PM}_{10}$ inlets. Thus, both Pallas and Summit have smaller aerosol particles than the rest of the stations according to $\alpha_{\mathrm{sp}}$ and very similar ones when compared with each other. If the 

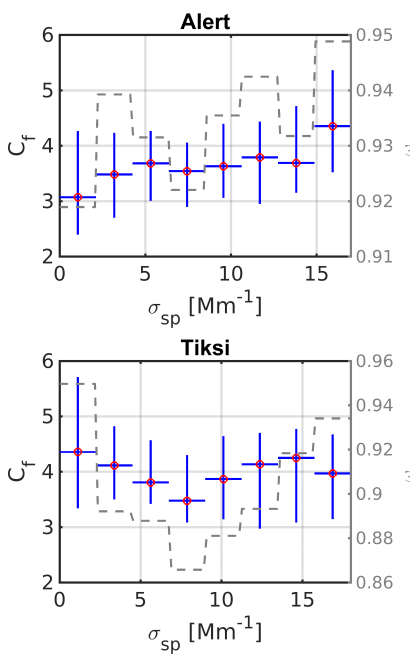
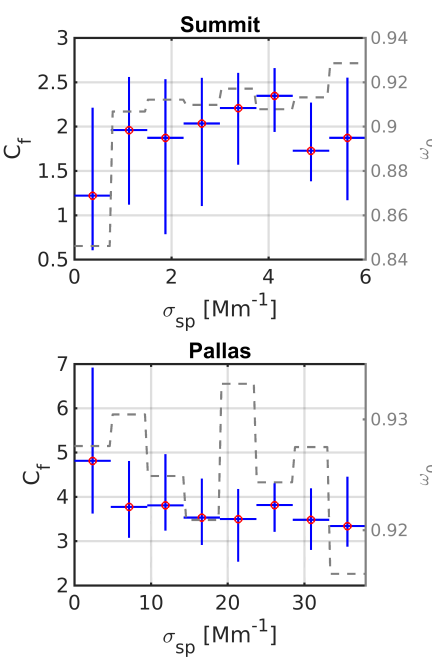
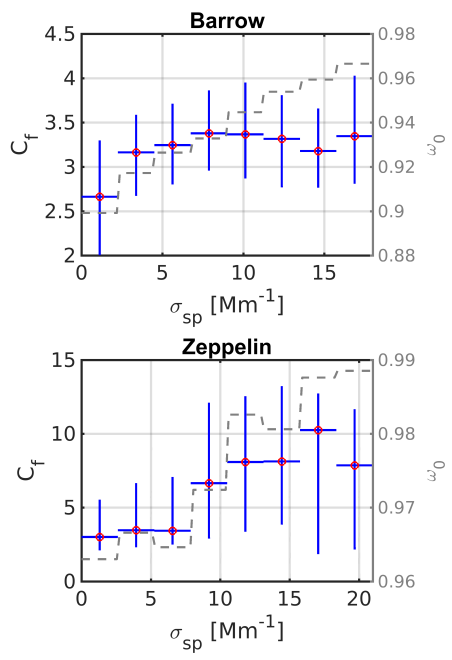

Figure 9. Aethalometer correction factor $C_{\mathrm{f}}$ as a function of light scattering coefficients $\left(\sigma_{\mathrm{sp}}\right)$. The right hand $y$ axis shows the median singlescattering albedo $\left(\omega_{0}\right)$ of the aerosol calculated using $\sigma_{\mathrm{ap}}$ from co-located light absorption photometers. The vertical whiskers represent the interquartile range (25th to 75 th percentile range) with the median shown as a red circle. The $C_{\mathrm{f}}, \sigma_{\mathrm{sp}}$, and $\omega_{0}$ values are at a wavelength of $637 \mathrm{~nm}$ for all stations, except for Zeppelin $(525 \mathrm{~nm})$.

$\mathrm{PM}_{2.5}$ inlet were to be the reason for a lower $C_{\mathrm{f}}$ at Summit, then Pallas should also have to be influenced since the MAAP at Pallas is behind a $\mathrm{PM}_{2.5}$ inlet. Also shown in Fig. 8 are aerosol back-scatter fractions $(b)$ which are related to the size of the aerosol and have been shown to affect Aethalometers (Virkkula et al., 2015). The site that resembles Summit the most, considering $\alpha_{\mathrm{sp}}, b$, and $\omega_{0}$ is Pallas. The Pallas Aethalometer was operated with a filter change interval of $8 \mathrm{~h}$ for most of the time, and therefore there are very few data points with an ATN above 10. Hence, it is questionable whether there are enough data to be able to draw conclusions about a trend in the $C_{\mathrm{f}}$ and ATN relationship for Pallas.

Also shown in Fig. 8 are the slopes $(k)$ of the ATN dependence. The slopes were calculated by linear regression to match the equation $\sigma_{\mathrm{ap}} / \sigma_{0}=1+k$. ATN that follows the notation of previous work (Virkkula et al., 2007, 2015). It is well known that light scattering by particles affects filterbased absorption photometers, which wrongly gets interpreted as light absorption, termed apparent absorption. For the co-located PSAP and CLAP instruments, this has been compensated for by subtracting a fraction of the light scattering from the light absorption (Bond et al., 1999; Ogren, 2010). For the co-located MAAP instruments, scattering correction is applied by the firmware (Petzold and Schönlinner, 2004). These corrections need not be enough for all types of aerosols, and a cross sensitivity to light scattering can remain (Müller et al., 2011). For $\sigma_{0}$, no scattering correction has been applied.

Figure 9 shows $C_{\mathrm{f}}$ as a function of $\sigma_{\mathrm{sp}}$. Since no scattering correction has been applied to $\sigma_{0}$ the expected behaviour is that $\sigma_{0}$ increases with $\sigma_{\mathrm{sp}}$. This seems to be the case for Alert, Summit, Barrow, and Zeppelin, with a clearer trend for Alert and Barrow. All stations that show an increasing trend of $C_{\mathrm{f}}$

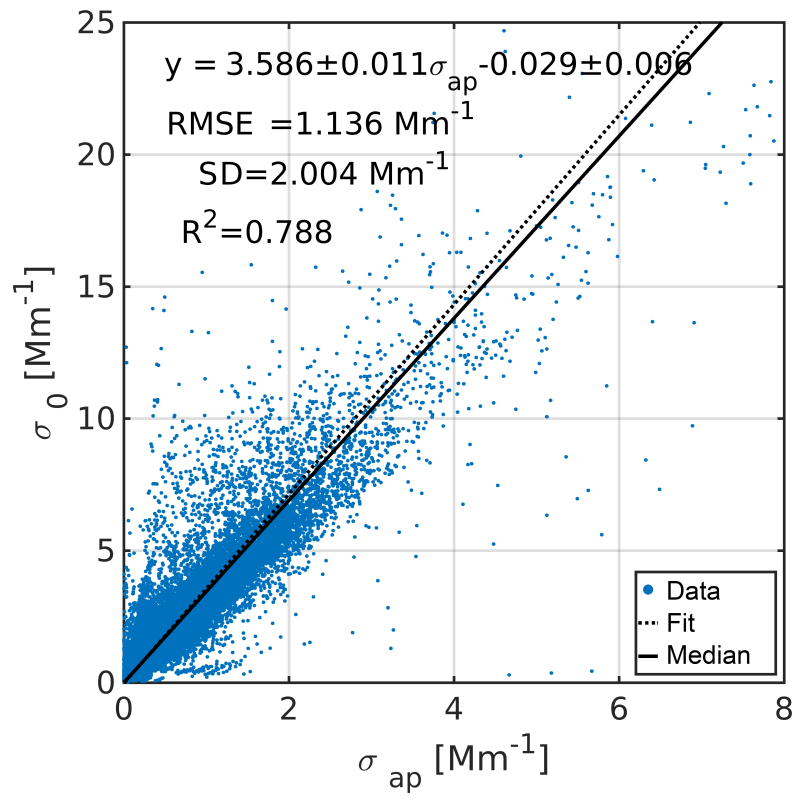

Figure 10. Attenuation coefficients $\left(\sigma_{0}\right)$ as a function of absorption coefficients $\left(\sigma_{\mathrm{ap}}\right)$ derived from co-located filter-based absorption photometers, including all available wavelengths and all stations except for Summit. To these data, using bivariate regression, a first order polynomial was fitted using averaging times as weights, shown as a dotted line. The solid line marks the weighted median $C_{\mathrm{f}}$ value of 3.45. In the figure, RMSE stands for systematic root-meansquare error and STD for standard deviation. The standard deviation was calculated using the standard error (SE) of the fit and number of data points $(n)$ as $\mathrm{SD}=\mathrm{SE} \cdot \sqrt{ } n \cdot R^{2}$ is the correlation coefficient. 
with $\sigma_{\text {sp }}$ have a co-located PSAP or a CLAP. It is possible that the non-compensation of $\sigma_{\mathrm{sp}}$ on $\sigma_{0}$ is further influenced by a too-large or too-small compensation of $\sigma_{\mathrm{sp}}$ on $\sigma_{\mathrm{ap}}$. Since $\sigma_{\text {ap }}$ is the denominator of Eq. (3), an overcompensation of apparent absorption would also cause $C_{\mathrm{f}}$ to increase with $\sigma_{\mathrm{sp}}$. Both stations that have a MAAP as the co-located instrument show a decreasing $C_{\mathrm{f}}$ as $\sigma_{\mathrm{sp}}$ increases.

Another possible explanation for a changing $C_{\mathrm{f}}$ with $\sigma_{\mathrm{sp}}$ can be that different levels of $\sigma_{\mathrm{sp}}$ are associated with different aerosol types and therefore also $C_{\mathrm{f}}$. Different levels of pollution can be associated with different sources of pollutants. These different sources could have different chemical and physical properties that could impact the $C_{\mathrm{f}}$ ratio. The right hand $y$ axis in Fig. 9 shows the median $\omega_{0}$ of the aerosol for the range of $\sigma_{\mathrm{sp}}$. The $C_{\mathrm{f}}$ value seems to follow the general trend of $\omega_{0}$ so that when $\omega_{0}$ increases, so does $C_{\mathrm{f}}$. It is not clear whether this is due to measurement artefacts or a difference in aerosol properties. The fact that the same behaviour is observed in Tiksi and Pallas indicates that the cross sensitivity to $\omega_{0}$ is not restricted to the PSAP and CLAP instruments.

In the upper part of Table 5, it can be seen that there is not much variation in the $C_{\mathrm{f}}$ values at different wavelengths. In the table, the Aethalometer data were interpolated using Ångström exponents to match the wavelength of the reference instruments using Eqs. (4) and (5). It cannot be ruled out that the low variability in $C_{\mathrm{f}}$ with wavelength is a consequence of the co-located instruments used. No multiwavelength long-term measurements of aerosol absorption coefficients from non-filter-based measurement instruments were available. The lower part of Table 5 provides statistics of $C_{\mathrm{f}}$ for each site. Because there does not seem to be a great wavelength dependence on the $C_{\mathrm{f}}$ value at Alert and Barrow, the $C_{\mathrm{f}}$ value for all wavelengths was calculated using all available wavelengths. The overall value of $C_{\mathrm{f}}$ for sites across the Arctic was determined to be 3.45. The value of 3.45 was calculated using average-time weighted median as discussed earlier, and the weighted 25 th and 75 th percentiles for the all wavelength $C_{\text {ref }}$ values are 2.93 and 4.15 , respectively. Because Summit appears to be significantly different from the other Arctic stations, the Summit $C_{\mathrm{f}}$ was omitted from the grand median $C_{\mathrm{f}}$ calculation.

Figure 10 depicts the relationship between the reference absorption instrument $\left(\sigma_{\mathrm{ap}}\right)$ and $\sigma_{0}$ which yields $C_{\mathrm{f}}$; see Eq. (3). The figure is provided as an overview comprising all wavelengths and all stations except for Summit, because of the reasoning mentioned before. In the figure, in addition to the weighted median value of 3.45 , the slope of the bivariate fit is also shown. The fit was performed using bivariate regression with the averaging time as weights (Cantrell, 2008). The slope of the bivariate regression becomes 3.59 (standard error 0.01). Both the regression method and the weighted median method yield values that are within $3 \%$ of each other. The root-mean-square error (RMSE) was calculated from the predicted $\sigma_{0}$ using the results from the regression, which becomes $1.14 \mathrm{Mm}^{-1}$.
The mass absorption cross section (MAC) describes the relationship between eBC mass concentrations and $\sigma_{\mathrm{ap}}$. Similarly, $\mathrm{MAC}_{\mathrm{AE}}$ describes the relationship between $\sigma_{0}$ and $\mathrm{eBC}$ as given by the manufacturer; both MAC and $\mathrm{MAC}_{\mathrm{AE}}$ have units of $\mathrm{m}^{2} \mathrm{~g}^{-1}$. A simple evaluation can be performed to investigate whether the $C_{\mathrm{f}}$ value is reasonable, assuming that the difference between $\mathrm{MAC}_{\mathrm{AE}}$ and $\mathrm{MAC}$ is $C_{\mathrm{f}}$ (Arnott et al., 2005). If the Aethalometer measured at a wavelength of $550 \mathrm{~nm}$, then $\mathrm{MAC}_{\mathrm{AE}}$ would be $26.59 \mathrm{~m}^{2} \mathrm{~g}^{-1}$. Compensating $\mathrm{MAC}_{\mathrm{AE}}$ with $C_{\mathrm{f}}=3.45$ would yield a MAC of $7.7 \mathrm{~m}^{2} \mathrm{~g}^{-1}$, i.e. a MAC which is 3.45 times lower than $\mathrm{MAC}_{\mathrm{AE}}$. This MAC is within the range suggested by Bond and Bergstrom (2006), namely $7.5 \pm 1.2 \mathrm{~m}^{2} \mathrm{~g}^{-1}$ at $550 \mathrm{~nm}$, which implies that the $C_{\mathrm{f}}$ value determined here is reasonable. This simple evaluation, however, does not take into account any apparent absorption or coating effects.

Multiple scattering correction factors $\left(C_{\text {ref }}\right)$ have been reported for a range of different sites around the world. Although the $C_{\mathrm{f}}$ values reported here cannot be considered to be equivalent to multiple scattering corrections, it is still useful to compare $C_{\mathrm{f}}$ with $C_{\text {ref. }}$. $C_{\text {ref }}$ values reported in the literature are summarised in Table 6.

Some of the variations in the reported $C_{\text {ref }}$ values of Table 6 can be attributed to the different ways in which they were calculated. Some $C_{\text {ref }}$ values were calculated with a filter loading correction applied and some without. Moreover, some of the $C_{\text {ref }}$ values were calculated with both a scattering and a filter loading correction applied. For the sake of inter-comparability, a $C_{\text {ref }}$ value calculated without any of the available correction algorithms would be preferable.

Comparing the grand median $C_{\mathrm{f}}$ value of 3.45 conceived here shows that it is well within the range of studies reporting $C_{\text {ref }}$ values. The values that are the closest are those by Collaud-Coen et al. (2010), which is not surprising since that study had light absorption coefficients from a MAAP as reference and not true reference absorption measurements. The $C_{\mathrm{f}}$ value of 3.45 conceived here is also close to 3.5, which is what the Global Atmospheric Watch's World Calibrations Centre for Aerosol Physics recommends using globally (GAW Report No. 227; http://wmo-gaw-wcc-aerosol-physics.org/ wmo-gaw-reports.html).

\section{Conclusions}

In clean environments, such as in the Arctic during summer months, measurements of aerosol light absorption coefficients can be below the detection limit of the instrument. Symptomatically, it is not uncommon to encounter measurements reporting negative equivalent black carbon concentrations or light absorption coefficients. These values are without physical meaning and originate from instrument noise and uncertainties. 
Table 6. Summary table of different multiple scattering enhancement factor $\left(C_{\text {ref }}\right)$ values reported in literature for different types of locations and therefore aerosol types.

\begin{tabular}{llrl}
\hline Site & Site or aerosol type & $C_{\text {ref }}$ & Citation \\
\hline Las Vegas, USA & Urban & 3.69 & Arnott et al. (2005) \\
Laboratory & Diesel soot & $2.09-2.22$ & Weingartner et al. (2003) \\
Amazon, Brazil & Biomass burning & 5.23 & Schmid et al. (2006) \\
Jungfraujoch, Switzerland & Free troposphere & $2.8-7.77$ & Collaud Coen et al. (2010) \\
Cabauw, Netherlands & Polluted continental & $4.09-4.57$ & Collaud Coen et al. (2010) \\
Mace Head, Ireland & Coastal & $3.05-3.83$ & Collaud Coen et al. (2010) \\
Hohenpeißenberg, Germany & Rural continental & $2.78-3.16$ & Collaud Coen et al. (2010) \\
Leipzig, Germany & Urban & $\sim 2.2-3.2$ & ACTRIS* \\
\hline
\end{tabular}

* ACTRIS WP3 report deliverable D3.16 (http://fp7.actris.eu/language/en-GB/Members/Deliverables.aspx).

Here a post-processing method for Aethalometer data based on collection time is elaborated on. This postprocessing approach allows for an arbitrary collection time $\Delta t$, which lowers the electronic noise of the Aethalometer proportionally to $\Delta t^{-1}$. In comparison, boxcar averaging lowers the noise proportional to $t_{\mathrm{avg}}^{-0.5}$. The greatest benefit of this approach can be achieved when drift in the Aethalometer ATN measurements is minimised.

The noise characteristics of Aethalometers are best estimated using measurements of particle-free air. Based on these measurements, it is recommended that particle-free air measurements should be conducted for at least $24 \mathrm{~h}$ or more. Furthermore, the absolute filter used for particle-free air measurements should be connected between the instrument and the sampling line from which the sample is drawn during normal operation. From these data, the electronic noise and drift can be evaluated.

The uncertainty analysis showed that the collection time approach can be used with a simple criterion that keeps the signal-to-noise ratio constant, namely that the postprocessing calculations are invoked once the filter attenuation of the instrument has changed by more than $\triangle \mathrm{ATN}$. This criterion will cause the collection time to vary according to the concentration of absorbing aerosol particles. The collection time approach was applied to Aethalometer data from six Arctic monitoring sites using $\Delta \mathrm{ATN} \geq 2$.

In addition, using co-located absorption photometer measurements at each site, an Arctic-specific Aethalometer correction factor $\left(C_{\mathrm{f}}\right)$ was calculated using the collection time approach as described above. This correction factor harmonises Aethalometer attenuation coefficients with light absorption coefficients as measured by the co-located light absorption photometers. For all wavelengths, and all lowaltitude Arctic stations (i.e. all stations except Summit), the median $C_{\mathrm{f}}$ value was calculated to be 3.45 . The 25 th to 75 th percentile range of $C_{\mathrm{f}}$ was $2.93-4.15$. The $C_{\mathrm{f}}$ value for Summit was calculated to be 1.61. The reason for the low $C_{\mathrm{f}}$ value at Summit remains unresolved.
Data availability. The source data used for this article are stored in the EBAS database operated by the Norwegian Institute for Air Research http://ebas.nilu.no. EBAS is a database for surface in-situ measurements stations around the globe and is used as data repository by several frameworks. One of these is the World Meteorological Organisation Global Atmosphere Watch World Data Centre for Aerosol that also provided the data management service. The final data product resulting from the work presented here constitutes a secondary dataset targeted at one single analysis, as opposed to data stored in EBAS, which is not filtered for a specific purpose. The secondary data set is archived at the respective repository provided by the Aerosols, Clouds, and Trace gases Research InfraStructure (ACTRIS). ACTRIS also provided quality assurance by instrument comparison workshops for some of the instruments used here. The final data set is available at https://doi.org/10.21336/gen.1 (Backman et al., 2017). 


\section{Appendix A}
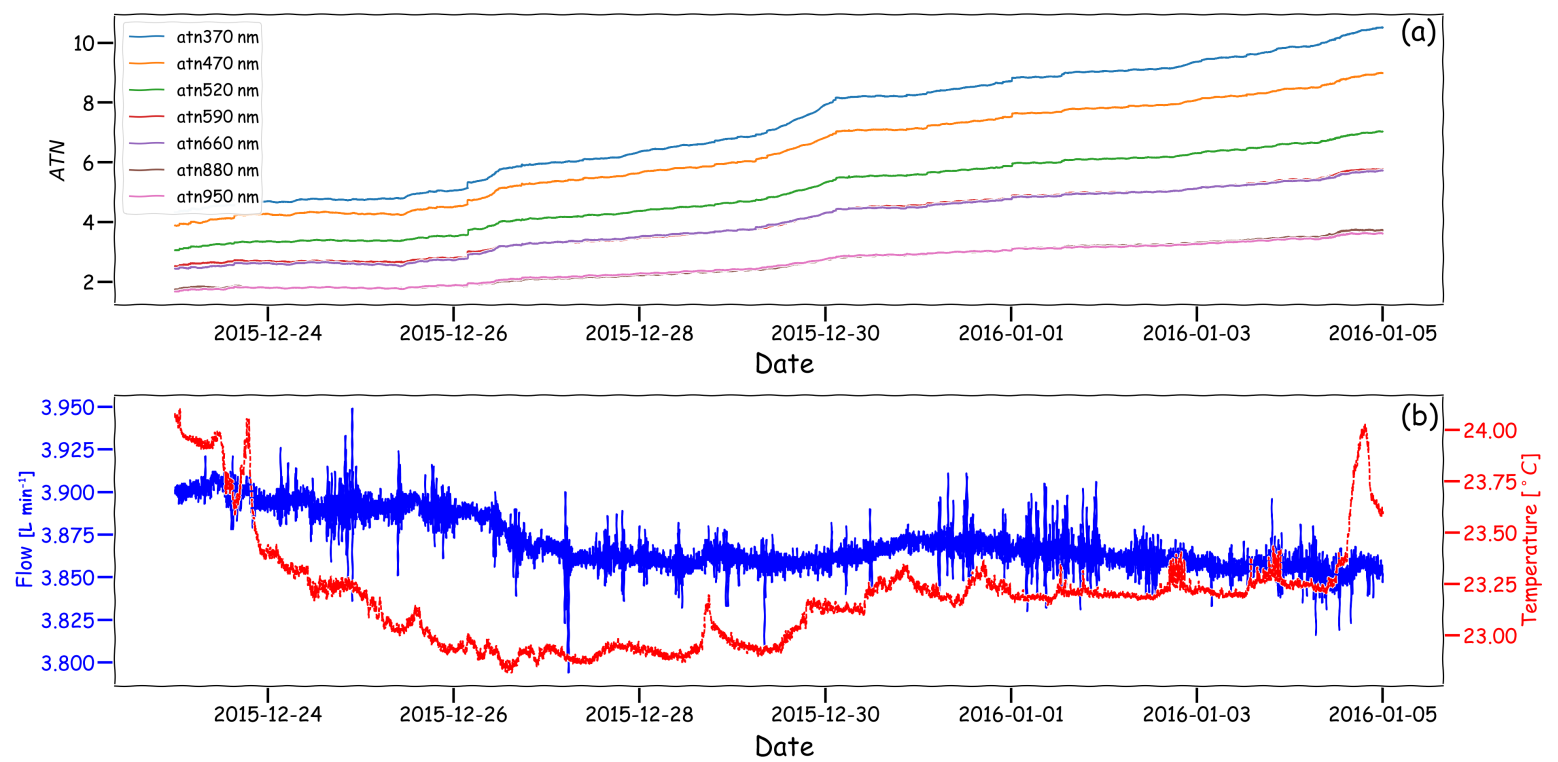

Figure A1. Time series of (a) ATN for all Aethalometer wavelengths and (b) measured Aethalometer flow rate and room temperature with an external flow meter (TSI Inc 4000 series).

Figure A1 shows the time series of the ATN for all wavelengths during the laboratory measurements with an absolute filter. The flow rate at the inlet of the Aethalometer was measured with a TSI 4000 series flow meter in front of the instrument and after the absolute filter. The temperature that was measured by the flow meter is also shown in the figure.

Figure A2 shows all wavelengths of ATN for the five Arctic stations where measurements were conducted for over $24 \mathrm{~h}$ with an absolute filter connected to the instruments sample inlet. 

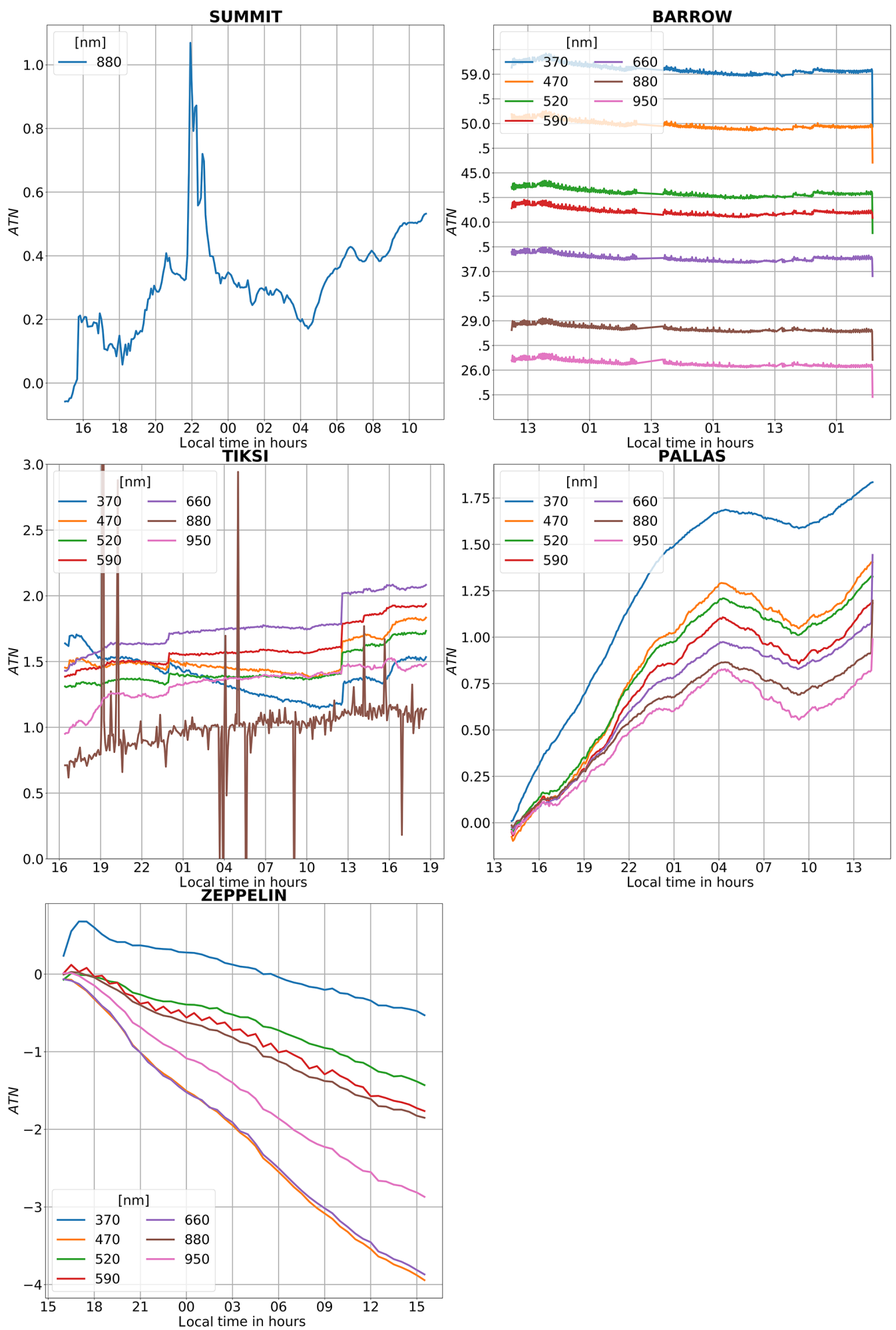

Figure A2. ATN for all wavelengths from the measurements with absolute filters connected to the sample inlet. Alert is not shown because the measurements were not conducted for more than a few hours although they were conducted regularly. 


\section{Appendix B}

The examination of the ATN dependence of an Aethalometer using a co-located absorption photometer requires the assumption that any remaining ATN dependence of the colocated instrument does not impact the ATN dependence of the Aethalometer substantially. An ATN dependence can be expressed as

$\sigma_{\mathrm{ap}}=(1+k \mathrm{ATN}) \sigma_{0}$,

where $\sigma_{\mathrm{ap}}$ is the light absorption coefficient that has no ATN dependence and $\sigma_{0}$ is an ATN-dependent light absorption coefficient. The term $k$ describes the magnitude of the ATN dependence (Virkkula et al., 2015).

Consider a time series with a constant light absorption coefficient of $2 \mathrm{Mm}^{-1}$. Solving $\sigma_{0}$ from Eq. (B1) yields the equation that can be used to produce ATN-dependent time series of both a hypothetical Aethalometer and PSAP. The Aethalometer was given a $k$ value of 0.002 . The value of 0.002 is for a high single-scattering albedo aerosol (Virkkula et al., 2015). A $k$ value of 0.001 was assigned to the hypothetical PSAP representing a non-ideal compensation of filter loading effects during data post-processing that would correspond to half the ATN dependence of the Aethalometer.

In order to achieve asynchronous filter changes, the ratio spot size area $(A)$ to flow rate $(Q)$ was chosen so that they differ. The Aethalometer was given a flow rate of $5 \mathrm{~L} \mathrm{~min}^{-1}$ and a spot size of $0.5 \mathrm{~cm}^{2}$. The PSAP was given a flow rate of $1.1 \mathrm{~L} \mathrm{~min}^{-1}$ and a spot size of $20 \mathrm{~mm}^{2}$. The time base for these calculations was $60 \mathrm{~min}$. The change in ATN was calculated as

$\Delta \mathrm{ATN}=\frac{\sigma_{0} Q \Delta t}{A}$.
From Eq. (B2), a time series was constructed from increments of ATN so that ATN was set to begin from 0 after a threshold of 85 was reached, thus simulating a filter change. The ATN time series was then applied to Eq. (B1) to produce two time series of $\sigma_{0}$ that both depend on ATN. Both time series are shown in the left panel of Fig. B1.

The ratio of $\sigma_{\mathrm{ap}} / \sigma_{0}$ was divided into ATN bins and plotted as a function of ATN (right panel of Fig. B1). Curve fitting to the median of each bin gives the $\sigma_{\mathrm{ap}} / \sigma_{0}$ ratio as a function of ATN, which is the equation $\sigma_{\mathrm{ap}} / \sigma_{0}=1+k \cdot \mathrm{ATN}$. The curve fit gives a $k$ value of the simulated Aethalometer of 0.00190 which is $5 \%$ less than expected (it should be 0.002). Varying the $k$ value of the co-located instrument between 0 and 0.004 yields $k$ values of the simulated Aethalometer that are between -2 and $-27 \%$ of from the expected $k$ values.

The same exercise was repeated for a randomly varying concentration that is shown in Fig. B2, which should represent a real world situation. The time series was generated using random numbers. Changing the $k$ value of the co-located instrument between 0 and 0.004 gives an ATN dependency that is between -2 and $-29 \%$ of the expected. It should be noted that more data points make the slope closer to the expected value of 0.002 . The ratio $\sigma_{\mathrm{ap}} / \sigma_{0}$ is equivalent to $C_{\mathrm{f}}^{-1}$ from the paper and should therefore support the interpretation of the ATN dependency of $C_{\mathrm{f}}$.
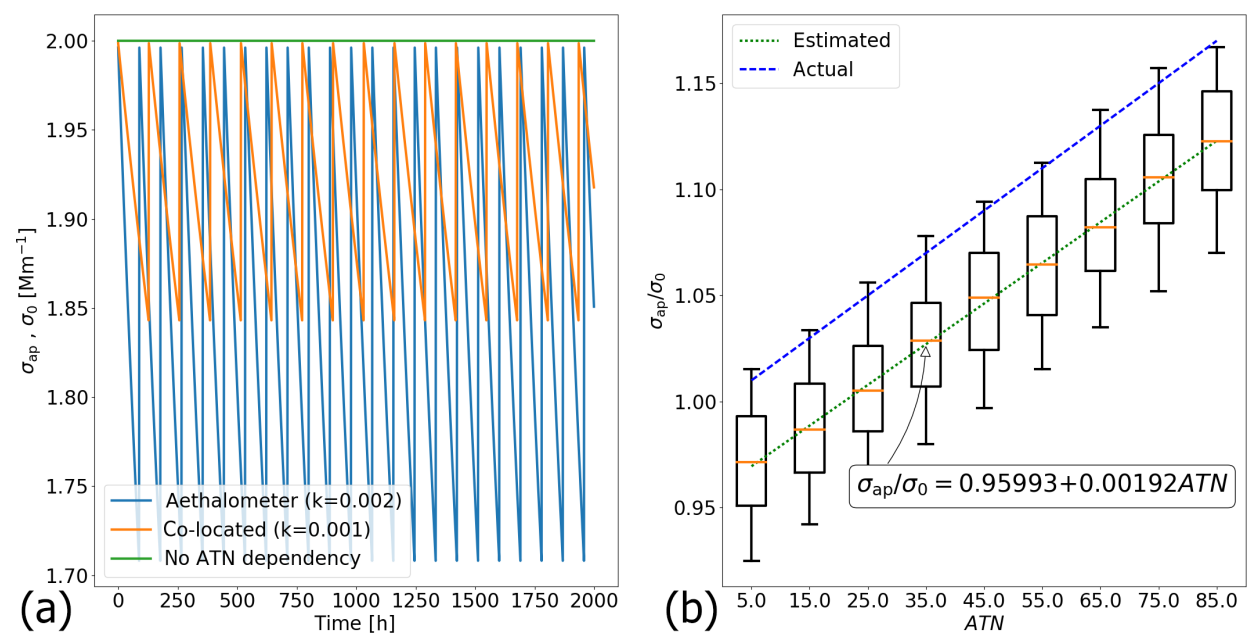

Figure B1. (a) shows the time series of an ATN-dependent $\sigma_{0}$ for a hypothetical Aethalometer and co-located PSAP so that the filter changes were not performed in synchronisation. The "No ATN dependency" in the figure legend denotes $\sigma_{\text {ap }}$ in Eq. (B1), from which both the hypothetical instrument ATN dependencies were calculated. (b) shows the ATN dependence of the Aethalometer when compared to the ATN-dependent co-located PSAP. 

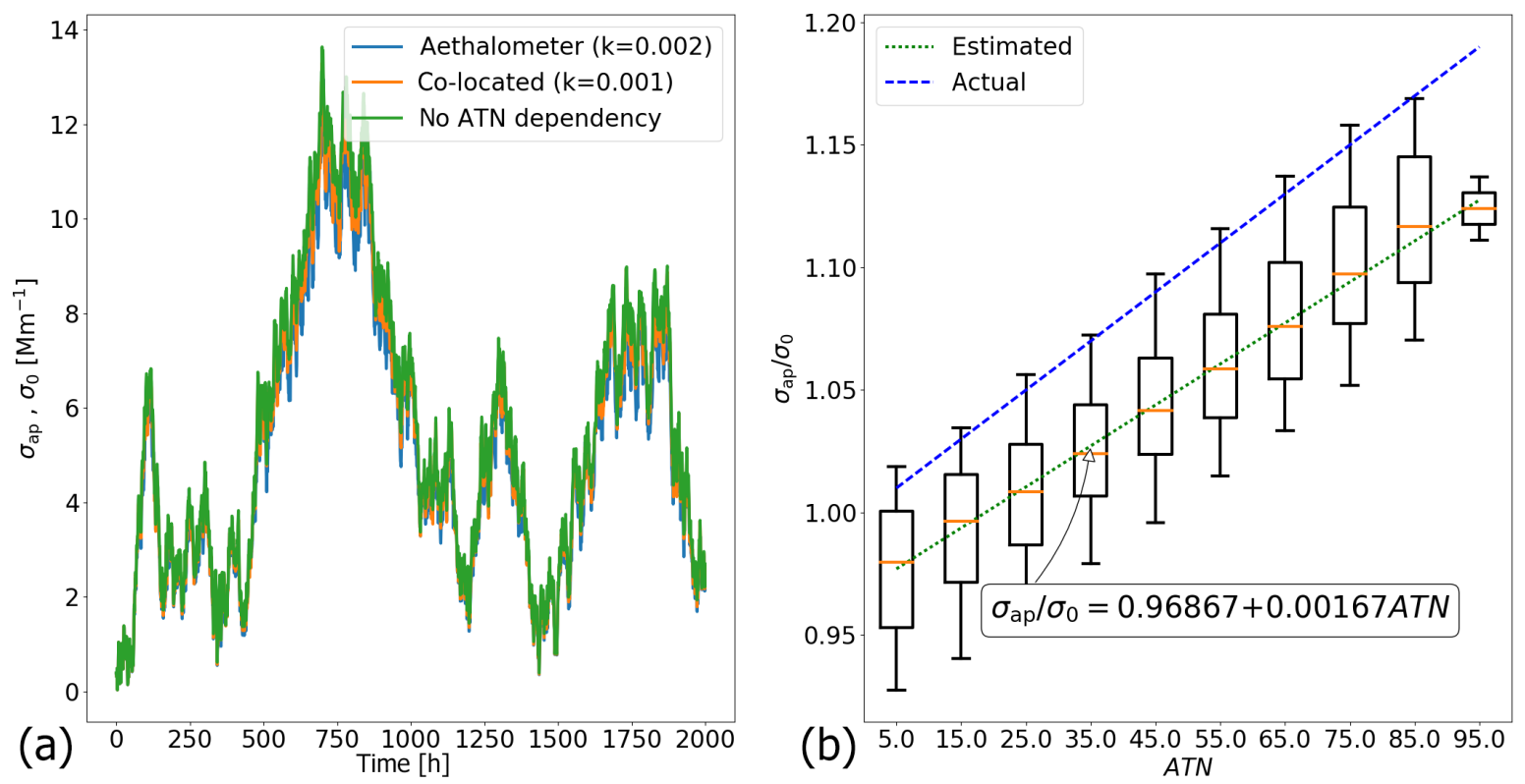

Figure B2. Same as Fig. B1 but with a variable concentration. Panel (a) shows the time series of a ATN-dependent $\sigma_{0}$ for a hypothetical Aethalometer and co-located PSAP so that the filter changes were not performed in synchronization. The "No ATN dependency" in the figure legend denotes $\sigma_{\mathrm{ap}}$ in Eq. (B1), from which both the hypothetical instrument ATN dependencies were calculated. Panel (b) shows the ATN dependence of the Aethalometer when compared to the ATN-dependent co-located PSAP. 
Competing interests. The authors declare that they have no conflict of interest.

Acknowledgements. This work was supported by the Academy of Finland project Greenhouse gas, aerosol and albedo variations in the changing Arctic (project number 269095), Novel Assessment of Black Carbon in the Eurasian Arctic: From Historical Concentrations and Sources to Future Climate Impacts (NABCEA, project number 296302), and the Academy of Finland Centre of Excellence program (project number 272041). John Backman wishes to acknowledge the Maj and Tor Nessling Foundation grants 2014044, 201600449, and 201700305 for financial support. We acknowledge Russel Schnell for providing Aethalometer data from Summit. The authors would like to acknowledge the Alert operators for lab and instrument maintenance and CFS Alert for the logistics and operations of the Alert base camp. More generally, the authors would like to acknowledge the personnel and researchers at the respective measurement stations that have contributed to the data. We acknowledge the Aerosol working group of the International Arctic System for Observing the Atmosphere (IASOA) for coordinating the data and expert contributions to this work. Data used in this article are archived and accessible from the EBAS database operated at the Norwegian Institute for Air Research (NILU) http://http://ebas.nilu.no. Data management is provided by the WMO Global Atmosphere Watch World Data Centre for Aerosol. This project has received funding from the European Union's Horizon 2020 research and innovation programme under grant agreement No 654109 (ACTRIS).

Edited by: Willy Maenhaut

Reviewed by: two anonymous referees

\section{References}

Anderson, T. L. and Ogren, J. A.: Determining aerosol radiative properties using the TSI 3563 integrating nephelometer, Aerosol Sci. Tech., 29, 57-69, https://doi.org/10.1080/02786829808965551, 1998.

Andreae, M. O. and Gelencsér, A.: Black carbon or brown carbon? The nature of light-absorbing carbonaceous aerosols, Atmos. Chem. Phys., 6, 3131-3148, https://doi.org/10.5194/acp-63131-2006, 2006.

Arnott, W. P., Hamasha, K., Moosmüller, H., Sheridan, P. J., and Ogren, J. A.: Towards aerosol light-absorption measurements with a 7-wavelength Aethalometer: Evaluation with a photoacoustic instrument and 3-wavelength nephelometer, Aerosol Sci. Tech., 39, 17-29, https://doi.org/10.1080/027868290901972, 2005 .

Asmi, E., Kondratyev, V., Brus, D., Laurila, T., Lihavainen, H., Backman, J., Vakkari, V., Aurela, M., Hatakka, J., Viisanen, Y., Uttal, T., Ivakhov, V., and Makshtas, A.: Aerosol size distribution seasonal characteristics measured in Tiksi, Russian Arctic, Atmos. Chem. Phys., 16, 1271-1287, https://doi.org/10.5194/acp16-1271-2016, 2016.

Backman, J., Virkkula, A., Vakkari, V., Beukes, J. P., Van Zyl, P. G., Josipovic, M., Piketh, S., Tiitta, P., Chiloane, K., Petäjä, T., Kulmala, M., and Laakso, L.: Differences in aerosol ab- sorption Ångström exponents between correction algorithms for a particle soot absorption photometer measured on the South African Highveld, Atmos. Meas. Tech., 7, 4285-4298, https://doi.org/10.5194/amt-7-4285-2014, 2014.

Backman, J., Schmeisser, L., Virkkula, A., Ogren, J. A., Asmi, E., Starkweather, S., Sharma, S., Eleftheriadis, K., Vratolis, S., Uttal, T., Tunved, P., Jefferson, A., Bergin, M., Makshtas, A., and Fiebig, M.: Time series of aerosol light-absorption coefficients from Aethalometers at six Arctic stations between 2012 and 2014, https://doi.org/10.21336/gen.1, 2017.

Bergstrom, R. W., Pilewskie, P., Russell, P. B., Redemann, J., Bond, T. C., Quinn, P. K., and Sierau, B.: Spectral absorption properties of atmospheric aerosols, Atmos. Chem. Phys., 7, 5937-5943, https://doi.org/10.5194/acp-7-5937-2007, 2007.

Bodhaine, B. A.: Aerosol measurements at four background sites, J. Geophys. Res., 88, 10753-10768, 1983.

Bodhaine, B. A.: Aerosol absorption measurements at Barrow, Mauna Loa, and the south pole, J. Geophys. Res., 100, 89678975, 1995.

Bond, T. C. and Bergstrom, R. W.: Light absorption by carbonaceous particles: An investigative review, Aerosol Sci. Tech., 40, 27-67, https://doi.org/10.1080/02786820500421521, 2006.

Bond, T. C., Anderson, T. L., and Campbell, D.: Calibration and intercomparison of filter-based measurements of visible light absorption by aerosols, Aerosol Sci. Tech., 30, 37-41, 1999.

Bond, T. C., Doherty, S. J., Fahey, D. W., Forster, P. M., Berntsen, T., DeAngelo, B. J., Flanner, M. G., Ghan, S., Kärcher, B., Koch, D., Kinne, S., Kondo, Y., Quinn, P. K., Sarofim, M. C., Schultz, M. G., Schulz, M., Venkataraman, C., Zhang, H., Zhang, S., Bellouin, N., Guttikunda, S. K., Hopke, P. K., Jacobson, M. Z., Kaiser, J. W., Klimont, Z., Lohmann, U., Schwarz, J. P., Shindell, D., Storelvmo, T., Warren, S. G., and Zender, C. S.: Bounding the role of black carbon in the climate system: A scientific assessment, J. Geophys. Res.-Atmos., 118, 5380-5552, https://doi.org/10.1002/jgrd.50171, 2013.

Cantrell, C. A.: Technical Note: Review of methods for linear least-squares fitting of data and application to atmospheric chemistry problems, Atmos. Chem. Phys., 8, 5477-5487, https://doi.org/10.5194/acp-8-5477-2008, 2008.

Cappa, C. D., Lack, D. A., Burkholder, J. B., and Ravishankara, A. R.: Bias in filter-based aerosol light absorption measurements due to organic aerosol loading: Evidence from laboratory measurements, Aerosol Sci. Tech., 42, 1022-1032, https://doi.org/10.1080/02786820802389285, 2008.

Collaud Coen, M., Weingartner, E., Apituley, A., Ceburnis, D., Fierz-Schmidhauser, R., Flentje, H., Henzing, J. S., Jennings, S. G., Moerman, M., Petzold, A., Schmid, O., and Baltensperger, U.: Minimizing light absorption measurement artifacts of the Aethalometer: evaluation of five correction algorithms, Atmos. Meas. Tech., 3, 457-474, https://doi.org/10.5194/amt-3-4572010, 2010.

Delene, D. J. and Ogren, J. A.: Variability of aerosol optical properties at four North American surface monitoring sites, J. Atmos. Sci., 59, 1135-1150, 2002.

Drinovec, L., Mocnik, G., Zotter, P., Prévôt, A. S. H., Ruckstuhl, C., Coz, E., Rupakheti, M., Sciare, J., Müller, T., Wiedensohler, A., and Hansen, A. D. A.: The "dual-spot" Aethalometer: an improved measurement of aerosol black carbon with real- 
time loading compensation, Atmos. Meas. Tech., 8, 1965-1979, https://doi.org/10.5194/amt-8-1965-2015, 2015.

Eleftheriadis, K., Vratolis, S., and Nyeki, S.: Aerosol black carbon in the European Arctic: Measurements at Zeppelin station, Ny-Ålesund, Svalbard from 1998-2007, Geophys. Res. Lett., 36, L02809, https://doi.org/10.1029/2008GL035741, 2009

Hadley, O. L. and Kirchstetter, T. W.: Black-carbon reduction of snow albedo, Nat. Clim. Chang., 2, 437-440, https://doi.org/10.1038/nclimate1433, 2012.

Hagler, G. S. W., Bergin, M. H., Smith, E. A., and Dibb, J. E.: A summer time series of particulate carbon in the air and snow at Summit, Greenland, J. Geophys. Res.-Atmos., 112, 1-12, https://doi.org/10.1029/2007JD008993, 2007.

Hagler, G. S. W., Yelverton, T. L. B., Vedantham, R., Hansen, A. D. A., and Turner, J. R.: Post-processing method to reduce noise while preserving high time resolution in Aethalometer realtime black carbon data, Aerosol Air Qual. Res., 11, 539-546, https://doi.org/10.4209/aaqr.2011.05.0055, 2011.

Hatakka, J., Aalto, T., Aaltonen, V., Aurela, M., Hakola, H., Komppula, M., Laurila, T., Lihavainen, H., Paatero, J., Salminen, K., and Viisanen, Y.: Overview of the atmospheric research activities and results at Pallas GAW station, Boreal Environ. Res., 8, 365-383, 2003.

Holland, M. M. and Bitz, C. M.: Polar amplification of climate change in coupled models, Clim. Dynam., 21, 221-232, https://doi.org/10.1007/s00382-003-0332-6, 2003.

Hyndman, R. J. and Fan, Y.: Sample quantiles in statistical packages, Am. Stat., 50, 361-365, https://doi.org/10.1017/CBO9781107415324.004, 1996.

Johannessen, O. M., Bengtsson, L., Miles, M. W., Kuzmina, S. I., Semenov, V. A., Alekseev, G. V., Nagurnyi, A. P., Zakharov, V. F., Bobylev, L. P., Pettersson, L. H., Hasselmann, K., and Cattle, H. P.: Arctic climate change: Observed and modelled temperature and sea-ice variability, Tellus Ser. A, 56, 328-341, https://doi.org/10.1111/j.1600-0870.2004.00060.x, 2004.

Koch, D. and Del Genio, A. D.: Black carbon semi-direct effects on cloud cover: review and synthesis, Atmos. Chem. Phys., 10, 7685-7696, https://doi.org/10.5194/acp-10-7685-2010, 2010.

Lack, D. A., Cappa, C. D., Covert, D. S., Baynard, T., Massoli, P., Sierau, B., Bates, T. S., Quinn, P. K., Lovejoy, E. R., and Ravishankara, A. R.: Bias in filter-based aerosol light absorption measurements due to organic aerosol loading: Evidence from ambient measurements, Aerosol Sci. Tech., 42, 1033-1041, https://doi.org/10.1080/02786820802389277, 2008.

Lack, D. A., Cappa, C. D., Cross, E. S., Massoli, P., Ahern, A. T., Davidovits, P., and Onasch, T. B.: Absorption enhancement of coated absorbing aerosols: Validation of the photo-acoustic technique for measuring the enhancement, Aerosol Sci. Tech., 43, 1006-1012, https://doi.org/10.1080/02786820903117932, 2009.

Miyazaki, Y., Kondo, Y., Sahu, L. K., Imaru, J., Fukushima, N., and Kano, M.: Performance of a newly designed continuous soot monitoring system (COSMOS), J. Environ. Monitor., 10, 11951201, https://doi.org/10.1039/b806957c, 2008.

Müller, T., Henzing, J. S., de Leeuw, G., Wiedensohler, A., Alastuey, A., Angelov, H., Bizjak, M., Collaud Coen, M., Engström, J. E., Gruening, C., Hillamo, R., Hoffer, A., Imre, K., Ivanow, P., Jennings, G., Sun, J. Y., Kalivitis, N., Karlsson, H., Komppula, M., Laj, P., Li, S.-M., Lunder, C., Marinoni, A., Martins dos Santos, S., Moerman, M., Nowak, A., Ogren, J. A., Pet- zold, A., Pichon, J. M., Rodriquez, S., Sharma, S., Sheridan, P. J., Teinilä, K., Tuch, T., Viana, M., Virkkula, A., Weingartner, E., Wilhelm, R., and Wang, Y. Q.: Characterization and intercomparison of aerosol absorption photometers: result of two intercomparison workshops, Atmos. Meas. Tech., 4, 245-268, https://doi.org/10.5194/amt-4-245-2011, 2011.

Nakayama, T., Kondo, Y., Moteki, N., Sahu, L. K., Kinase, T., Kita, K., and Matsumi, Y.: Size-dependent correction factors for absorption measurements using filter-based photometers: PSAP and COSMOS, J. Aerosol Sci., 41, 333-343, https://doi.org/10.1016/j.jaerosci.2010.01.004, 2010.

Ogren, J. A., Wendell, J., Andrews, E., and Sheridan, P. J.: Continuous Light Absorption Photometer for Long-Term Studies, Atmos. Meas. Tech., https://doi.org/10.5194/amt-10-4805-2017, 2017.

Ogren, J. A.: Comment on "Calibration and intercomparison of filter-based measurements of visible light absorption by aerosols", Aerosol Sci. Tech., 44, 589-591, https://doi.org/10.1080/02786826.2010.482111, 2010.

Petzold, A. and Schönlinner, M.: Multi-angle absorption photometry-a new method for the measurement of aerosol light absorption and atmospheric black carbon, J. Aerosol Sci., 35, 421-441, https://doi.org/10.1016/j.jaerosci.2003.09.005, 2004.

Petzold, A., Schloesser, H., Sheridan, P. J., Arnott, W. P., Ogren, J. A., and Virkkula, A.: Evaluation of multiangle absorption photometry for measuring aerosol light absorption, Aerosol Sci. Tech., 39, 40-51, https://doi.org/10.1080/027868290901945, 2005.

Petzold, A., Ogren, J. A., Fiebig, M., Laj, P., Li, S.-M., Baltensperger, U., Holzer-Popp, T., Kinne, S., Pappalardo, G., Sugimoto, N., Wehrli, C., Wiedensohler, A., and Zhang, X.-Y.: Recommendations for reporting "black carbon" measurements, Atmos. Chem. Phys., 13, 8365-8379, https://doi.org/10.5194/acp13-8365-2013, 2013.

Schmid, O., Artaxo, P., Arnott, W. P., Chand, D., Gatti, L. V., Frank, G. P., Hoffer, A., Schnaiter, M., and Andreae, M. O.: Spectral light absorption by ambient aerosols influenced by biomass burning in the Amazon Basin. I: Comparison and field calibration of absorption measurement techniques, Atmos. Chem. Phys., 6, 3443-3462, https://doi.org/10.5194/acp-6-3443-2006, 2006.

Serreze, M. C. and Barry, R. G.: Processes and impacts of Arctic amplification: A research synthesis, Global Planet. Change, 77, 85-96, https://doi.org/10.1016/j.gloplacha.2011.03.004, 2011.

Serreze, M. C., Barrett, A. P., Stroeve, J. C., Kindig, D. N., and Holland, M. M.: The emergence of surface-based Arctic amplification, The Cryosphere, 3, 11-19, https://doi.org/10.5194/tc-311-2009, 2009.

Sharma, S., Brook, J. R., Cachier, H., Chow, J., Gaudenzi, A., and Lu, G.: Light absorption and thermal measurements of black carbon in different regions of Canada, J. Geophys. Res., 107, 4771, https://doi.org/10.1029/2002JD002496, 2002.

Sharma, S., Andrews, E., Barrie, L. A., Ogren, J. A., and Lavoué, D.: Variations and sources of the equivalent black carbon in the high Arctic revealed by long-term observations at Alert and Barrow: 1989-2003, J. Geophys. Res., 111, D14208, https://doi.org/10.1029/2005JD006581, 2006.

Sharma, S., Ishizawa, M., Chan, D., Lavoué, D., Andrews, E., Eleftheriadis, K., and Maksyutov, S.: 16-year simulation of Arctic black carbon: Transport, source contribution, and sensitivity 
analysis on deposition, J. Geophys. Res.-Atmos., 118, 943-964, https://doi.org/10.1029/2012JD017774, 2013.

Sheridan, P. J., Arnott, W. P., Ogren, J. A., Andrews, E., Atkinson, D. B., Covert, D. S., Moosmüller, H., Petzold, A., Schmid, B., Strawa, A. W., Varma, R., and Virkkula, A.: The Reno aerosol optics study: An evaluation of aerosol absorption measurement methods, Aerosol Sci. Tech., 39, 1-16, https://doi.org/10.1080/027868290901891, 2005.

Sherman, J. P., Sheridan, P. J., Ogren, J. A., Andrews, E., Hageman, D., Schmeisser, L., Jefferson, A., and Sharma, S.: A multi-year study of lower tropospheric aerosol variability and systematic relationships from four North American regions, Atmos. Chem. Phys., 15, 12487-12517, https://doi.org/10.5194/acp-15-124872015, 2015.

Springston, S. R. and Sedlacek, A. J.: Noise characteristics of an instrumental particle absorbance technique, Aerosol Sci. Tech., 41, 1110-1116, https://doi.org/10.1080/02786820701777457, 2007.

Virkkula, A., Ahlquist, N. C., Covert, D. S., Arnott, W. P., Sheridan, P. J., Quinn, P. K., and Coffman, D. J.: Modification, calibration and a field test of an instrument for measuring light absorption by particles, Aerosol Sci. Tech., 39, 68-83, https://doi.org/10.1080/027868290901963, 2005.

Virkkula, A., Mäkelä, T., Hillamo, R., Yli-Tuomi, T., Hirsikko, A., Hämeri, K., and Koponen, I. K.: A simple procedure for correcting loading effects of aethalometer data, J. Air Waste Manage. Assoc., 57, 1214-1222, https://doi.org/10.3155/10473289.57.10.1214, 2007.
Virkkula, A., Chi, X., Ding, A., Shen, Y., Nie, W., Qi, X., Zheng, L., Huang, X., Xie, Y., Wang, J., Petäjä, T., and Kulmala, M.: On the interpretation of the loading correction of the aethalometer, Atmos. Meas. Tech., 8, 4415-4427, https://doi.org/10.5194/amt8-4415-2015, 2015.

Weingartner, E., Saathoff, H., Schnaiter, M., Streit, N., Bitnar, B., and Baltensperger, U.: Absorption of light by soot particles: determination of the absorption coefficient by means of aethalometers, J. Aerosol Sci., 34, 1445-1463, https://doi.org/10.1016/S0021-8502(03)00359-8, 2003.

Wiscombe, W. J. and Warren, S. G.: A model for the spectral albedo of snow. I: Pure snow, J. Atmos. Sci., $\quad 37, \quad 2712-2733, \quad$ https://doi.org/10.1175/15200469(1980)037<2734:AMFTSA>2.0.CO;2, 1980a.

Wiscombe, W. J. and Warren, S. G.: A model for the spectral albedo of snow. II: Snow containing atmospheric aerosols, J. Atmos. Sci., 37, 2734-2745, https://doi.org/10.1175/15200469(1980)037<2734:AMFTSA>2.0.CO;2, 1980b. 